\title{
4 Density, molar volume and surface tension of liquid Al-Ti
}

5

6 J. J. Wessing ${ }^{1 *}$, J. Brillo ${ }^{1}$

7

$8{ }^{1}$ Institute of Materials Physics in Space, German Aerospace Center (DLR), 51170 Köln, 9 Germany

10

11

12

13

14

$15{ }^{*}$ Corresponding author:

16 Johanna Wessing

17 Institute of Materials Physics in Space,

18 German Aerospace Center (DLR), 51170 Köln, Germany

19 Tel.: +4922036013757

$20 \quad$ Fax: +49 220360161768

21 E-Mail: Johanna.Wessing@dlr.de

22

23 


\section{Abstract}

Al-Ti based alloys are of enormous technical relevance due to their specific properties. For studies in atomic dynamics, surface physics and industrial processing the precise knowledge of the thermophysical properties of the liquid phase is crucial. In the present work, we systematically measure mass density, $\rho\left[\mathrm{gcm}^{-3}\right]$, and the surface tension, $\gamma\left[\mathrm{Nm}^{-1}\right]$, as functions of temperature, $T$, and compositions of binary Al-Ti melts. Electromagnetic levitation in combination with the optical dilatometry method is used for density measurements and the oscillating drop method for surface tension measurements. It is found that, for all compositions, density and surface tension increase linearly upon decreasing temperature in the liquid phase. Within the Al-Ti system we find the largest values for pure titanium and the smallest for pure aluminum, which amount to $\rho(\mathrm{L}, \mathrm{Ti})=4.12 \pm 0.04 \mathrm{gcm}^{-3}$ and $\left.\chi_{\mathrm{L}, \mathrm{Ti}}\right)=1.56 \pm 0.02 \mathrm{Nm}^{-1}$ and $\rho(\mathrm{L}, \mathrm{Al})=2.09 \pm 0.01 \mathrm{gcm}^{-3}$ and $\left.\chi_{\mathrm{L}, \mathrm{Al}}\right)=0.87 \pm 0.06 \mathrm{Nm}^{-1}$, respectively. The data are analyzed concerning the temperature coefficients, $\rho_{\mathrm{T}}$ and $\gamma_{\mathrm{T}}$, excess molar volume, $V^{\mathrm{E}}$, excess surface tension, $\gamma^{\mathrm{E}}$, and surface segregation of the surface active component, Al. The results are compared with thermodynamic models. Generally, it is found that $\mathrm{Al}-\mathrm{Ti}$ is a highly nonideal system. (1) 1 2 3

\section{Keywords}

Al-Ti-alloys, density, surface tension, electromagnetic levitation, Butler model, Chatain model 


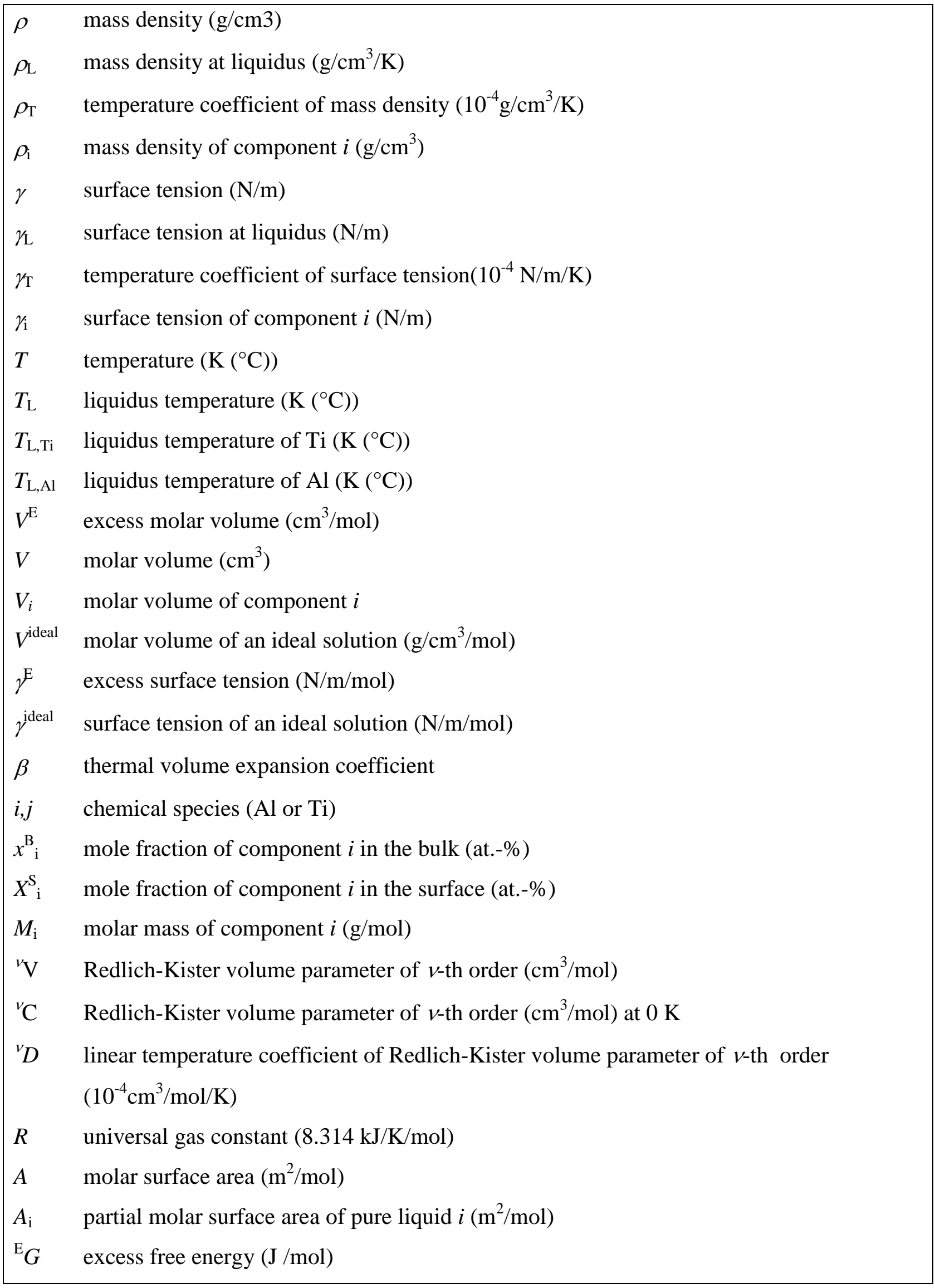




\begin{tabular}{|c|c|}
\hline${ }^{\mathrm{E}} G_{\mathrm{i}}^{\mathrm{B}}$ & partial excess free energy of component $i$ in the bulk $(\mathrm{kJ} / \mathrm{mol})$ \\
\hline${ }^{\mathrm{E}} G_{\mathrm{i}}^{\mathrm{S}}$ & partial excess free energy of component $i$ in the surface $(\mathrm{kJ} / \mathrm{mol})$ \\
\hline$f$ & geometrical factor \\
\hline$N_{\text {Av }}$ & Avogadro constant $\left(6.02310^{23} \mathrm{~mol}^{-1}\right)$ \\
\hline$\xi$ & factor accounting for a reduced coordination number in the surface \\
\hline$k$ & number of surface layers in the Chatain model \\
\hline$n$ & index of surface layer in the Chatain model \\
\hline$x^{(n)}{ }_{i}$ & mole fraction of component $i$ in the $n$-th surface layer \\
\hline$z$ & coordination number \\
\hline$Z_{1}$ & lateral coordination number \\
\hline$Z_{\mathrm{v}}$ & vertical coordination number \\
\hline$\Phi_{\mathrm{i}, \mathrm{j}}$ & single bond energy for a bond between atoms $i$ and $j(\mathrm{~J} / \mathrm{mol})$ \\
\hline$\omega$ & regular solution constant $(\mathrm{J} / \mathrm{mol})$ \\
\hline${ }^{v} L$ & Redlich-Kister coefficient of $v$-th order for the free energy $(\mathrm{J} / \mathrm{mol})$ \\
\hline${ }^{v} u(T)$ & Redlich-Kister coefficient of $v$-th order for the surface tension $(\mathrm{N} / \mathrm{m} / \mathrm{mol})$ \\
\hline$T_{\mathrm{P}}$ & pyrometer signal (K) \\
\hline$T_{\mathrm{L}, \mathrm{P}}$ & pyrometer signal at liquidus (K) \\
\hline$R d$ & droplet radius (m) \\
\hline$\varphi$ & azimuthal angle \\
\hline$a_{1}$ & $l$-th edge curve coefficient \\
\hline$P_{1}$ & l-th Legendre polynomial \\
\hline$l$ & index \\
\hline$V_{\mathrm{P}}$ & droplet volume in pixel units (pixel ${ }^{3}$ ) \\
\hline${ }^{\mathrm{drop}} V$ & real droplet volume $\left(\mathrm{cm}^{3}\right)$ \\
\hline$q$ & scaling factor $\left(\mathrm{cm}^{3} / \mathrm{pixel}^{3}\right)$ \\
\hline$\Omega$ & mean translational frequency $\left(\mathrm{s}^{-1}\right)$ \\
\hline$\omega \mathrm{x}$ & translational frequency in $\mathrm{x}$-direction $\left(\mathrm{s}^{-1}\right)$ \\
\hline$\omega \mathrm{y}$ & translational frequency in $y$-direction $\left(\mathrm{s}^{-1}\right)$ \\
\hline$\omega \mathrm{Z}$ & translational frequency in $\mathrm{z}$-direction $\left(\mathrm{s}^{-1}\right)$ \\
\hline$\omega_{\mathrm{m}}$ & surface oscillation frequency of mode $m\left(\mathrm{~s}^{-1}\right)$ \\
\hline$g$ & gravitational acceleration $\left(\mathrm{N} / \mathrm{m}^{2}\right)$ \\
\hline$R_{0}$ & radius of the sample with spherical shape (m) \\
\hline$p_{\mathrm{O} 2}^{\mathrm{S}}$ & partial pressure of oxygen in the vicinity of the surface $(\mathrm{Pa})$ \\
\hline
\end{tabular}




\begin{tabular}{|ll|}
\hline$K$ & equilibrium constant $(\mathrm{J} / \mathrm{mol})$ \\
$p^{\mathrm{Ch}}{ }_{\text {O2 }}$ & partial pressure of oxygen in the chamber $(\mathrm{Pa})$ \\
$D_{\mathrm{O}}$ & diffusion constant of oxygen in the vapor $\left(\mathrm{m}^{2} / \mathrm{s}\right)$ \\
$D_{\mathrm{Ox}}$ & diffusion constant of oxide in the vapor $\left(\mathrm{m}^{2} / \mathrm{s}\right)$ \\
\hline
\end{tabular}




\section{Introduction}

51

52

53

\subsection{Al-Ti}

The increasing need for more sophisticated materials in various high-temperature applications can potentially be satisfied by using Ti-based intermetallics. Even at elevated temperatures, $\gamma$ Al-Ti alloys combine a low density with a high tensile strength. This makes them particularly interesting for applications in the automotive or aerospace industries. For instance, they can be used as turbine blades in aircraft engines or as fuselage materials.

In addition, $(\alpha+\beta)$-TiAl may also be used in medical applications as bone implants, because of their bio-compatibility and corrosion resistance. They also exhibit comparatively low densities and, compared to conventional implants made of Co-Cr- or Fe-based alloys, a small Young modulus of approximately $110 \mathrm{GPa}$. Compared to the Young-modulus of bones of approximately $25 \mathrm{GPa}$ this is still high so further optimization of the material is necessary. Therefore, developing a profound understanding of the liquid phase is indispensable, as the vast majority of materials are directly produced from the melt by casting [1]. Among the properties relevant in this context, density and surface tension of the liquid phase are of pronounced importance.

Density is a fundamental material property. Its knowledge is crucial for casting processes and for determining surface tension from the measured raw data.

Surface tension plays a critical role for the castability of an alloy, and for the mould-filling capability. The latter is often problematic in Ti-based alloys. Both properties also reveal interesting academic science as they are strongly affected by processes taking place at the atomic scale.

Despite the technical importance of density and surface tension, data on these properties of Ti-based alloys are sparse. The main reason for this is the high chemical reactivity of liquid Ti 
paired with a large solubility of oxygen. This renders its investigation with conventional techniques extremely difficult. Nevertheless, there are containerbased methods, that have been used to investigate thermophysical properties of pure Ti and binary and multicomponent AlTi alloys, including the pendant [2] and sessile drop method [3]. Common methods for the determination of density and surface tension are listed in Table 1 . The sessile drop method is applied to calculate the surface tension of a sessile drop, using the equilibrium dependence between the forces of surface tension and gravity. Additionally, density can be obtained from the drop profile by assuming axis-symmetry. When dealing with extremely reactive systems, such as Al-Ti, the difficulty of that method lies in finding an adequate inert substrate material that shows negligible interactions with the sample [2]. In the case of the pendant drop similar theoretical approaches are applied on liquid droplets, which are squeezed through a capillary. The advantage of the pendant drop method is that the contact of the sample with the capillary stays relatively short compared to the substrate contact [3]. Literature data on Ti and industrially used multicomponent alloys, such as $\mathrm{Al}_{46} \mathrm{Ti}_{46} \mathrm{X}_{8}, \mathrm{X}=\mathrm{Nb}$, Ta and $\mathrm{Al}_{6} \mathrm{Ti}_{90} \mathrm{~V}_{4}$, along with their density and surface tension data are published in Refs. [1,4-23].

Typically, the main purpose of these investigations is the creation and completing of materials databases. However, if a detailed understanding of the system is envisaged, one must, perform measurements in which the composition is systematically varied [24].

The binary system Al-Ti is a good starting point for such investigations. To understand multicomponent systems, their binary basis must firstly be understood. Surprisingly, even for the binary system $\mathrm{Al}-\mathrm{Ti}$, data exist only in exceptional cases, such as for $\mathrm{Al}_{80} \mathrm{Ti}_{20}$ [25]. Therefore, the goal of the present work is to deliver systematically measured density and surface tension data on binary liquid Al-Ti alloys. Using electromagnetic levitation avoids pollution of the materials due to reactions with the container walls. Thus, the negative effects of the high chemical reactivity of the material are minimized. However, the interactions with 


$$
\rho_{\mathrm{T}}=-\beta \cdot \rho_{\mathrm{L}}
$$

114 For a binary solution of components $i(i=\mathrm{Al}, \mathrm{Ti})$, with respective mole fractions $x^{\mathrm{B}}{ }_{\mathrm{i}}$ and

115 molar masses $M_{\mathrm{i}}$, the molar volume of the solution, $V=\rho^{-1} \sum x^{\mathrm{B}}{ }_{\mathrm{i}} M_{\mathrm{i}}$, is generally represented by 116

$$
\text { [24]: }
$$

$V=V^{\mathrm{i}}+V^{\mathrm{E}}$

117 with:

$$
V^{\text {ideal }}=\sum_{\mathrm{i}=\mathrm{Al}}^{\mathrm{Ti}} x_{\mathrm{i}}^{\mathrm{B}} \frac{M_{\mathrm{i}}}{\rho_{\mathrm{i}}}
$$

118 Where $\rho_{\mathrm{I}}$ is the density of the pure substance $i$ at temperature $T . V^{\complement}$ is the excess volume and 119 the index "B" of the mole fraction marks the amount of element $i$ in the bulk. 
120 For $V^{\mathrm{E}}=0$, Eq. (3) reduces to a simple linear combination of the molar volumes of the pure

121 liquid elements, $V_{\mathrm{i}}=M_{\mathrm{i}} / \rho_{\mathrm{i}}$, and is designated as “ideal”.

122 Generally, $V^{E}$ depends on the temperature and the mole fraction. A simple expression of $V^{E}$ is

123 given by the following Redlich-Kister-type-Ansatz [24]:

$V^{\mathrm{E}}=x_{\mathrm{Al}}^{\mathrm{B}} x_{\mathrm{Ti}}^{\mathrm{B}}\left(\sum_{v=0}{ }^{v} V(T)\left(x_{\mathrm{Al}}^{\mathrm{B}}-x_{\mathrm{Ti}}^{\mathrm{B}}\right)^{v}\right)$

124 The parameters ${ }^{v} V(T)$ represent the interaction between the elements $\mathrm{Al}$ and $\mathrm{Ti}$ in the alloy

125 melt. As a first approximation, these parameters can be assumed to be linear functions of

126 temperature with parameters ${ }^{v} C={ }^{v} V\left(0 \mathrm{~K}\left(-273.15^{\circ} \mathrm{C}\right)\right)$ and $D^{v}=\partial^{v} V / \partial T$ :

${ }^{v} V(T)={ }^{v} C+{ }^{v} D T$

127

128

129

130

$\gamma(T)=\gamma_{\mathrm{L}}+\gamma_{\mathrm{T}}\left(T-T_{\mathrm{L}}\right)$

131

132

133

134

135

136

$$
\begin{aligned}
& \gamma=\gamma_{\mathrm{Al}}+\frac{R T}{A_{\mathrm{Al}}} \ln \left(\frac{x_{\mathrm{Al}}^{\mathrm{S}}}{x_{\mathrm{Al}}^{\mathrm{B}}}\right)+\frac{1}{A_{\mathrm{Al}}}\left({ }^{\mathrm{E}} G_{\mathrm{Al}}^{\mathrm{S}}\left(\mathrm{T}, x_{\mathrm{Al}}^{\mathrm{S}}, x_{\mathrm{Ti}}^{\mathrm{S}}\right)-{ }^{\mathrm{E}} G_{\mathrm{Al}}^{\mathrm{B}}\left(\mathrm{T}, x_{\mathrm{Al}}^{\mathrm{B}}, x_{\mathrm{Ti}}^{\mathrm{B}}\right)\right) \\
& =\gamma_{\mathrm{Ti}}+\frac{R T}{A_{\mathrm{Ti}}} \ln \left(\frac{x_{\mathrm{Ti}}^{\mathrm{S}}}{x_{\mathrm{Ti}}^{\mathrm{B}}}\right)+\frac{1}{A_{\mathrm{Ti}}}\left({ }^{\mathrm{E}} G_{\mathrm{Al}}^{\mathrm{S}}\left(\mathrm{T}, x_{\mathrm{Al}}^{\mathrm{S}}, x_{\mathrm{Ti}}^{\mathrm{S}}\right)-{ }^{\mathrm{E}} G_{\mathrm{Al}}^{\mathrm{B}}\left(\mathrm{T}, x_{\mathrm{Al}}^{\mathrm{B}}, x_{\mathrm{Ti}}^{\mathrm{B}}\right)\right)
\end{aligned}
$$

137 Here, $R$ is the universal gas constant, and ${ }^{\mathrm{E}} G_{\mathrm{i}}^{\mathrm{B}}$ and ${ }^{\mathrm{E}} G_{\mathrm{i}}^{\mathrm{S}}$ denote the respective partial excess

138 free energies of component $i$ in the bulk and in the surface layer. $A_{\mathrm{i}}$ is the partial molar surface 

pure elements $V_{\mathrm{i}}$ :

$A_{\mathrm{i}}=f V^{2 / 3} N_{\mathrm{Av}}^{1 / 3}$

141 In Eq. (9) $N_{\mathrm{Av}}$ is the Avogadro number, and $f$ is a geometrical factor. The value of $f$ depends

area of pure liquid $i$, approximated by the following expression from the molar volumes of the on the structures assumed for the surface and the bulk. For liquids, the commonly used value of 1.09 has recently been regarded as too high [40]. A more reasonable value of $f=1.0$ has been proposed by Kaptay [40] which is also used in the present work.

The main assumption of the Butler model is the approximation of the surface excess free energy ${ }^{\mathrm{E}} G_{\mathrm{i}}^{\mathrm{S}}\left(T,{ }^{\mathrm{S}} x_{\mathrm{i}}\right)$ by ${ }^{\mathrm{E}} G^{\mathrm{S}}\left(T,{ }^{\mathrm{S}} x_{\mathrm{i}}\right)=\xi^{\mathrm{E}} G^{\mathrm{B}}{ }_{\mathrm{i}}\left(T,{ }^{\mathrm{S}} x_{\mathrm{i}}\right)$, where the factor $\xi$ accounts for the reduced coordination of atoms in the surface layer. It can be approached as the ratio of the respective coordination numbers of atoms in the surface and the bulk. A constant value of 0.75 was initially suggested by Tanaka and Iida [41] as default approximation for liquids with unknown structure. Later, they adjusted this value to 0.83 [42]. In this study, however, we use 0.75 in order to comply with the Chatain model that is also applied. Solving Eq. (9) yields the surface tension of the alloy and the concentration in the surface layer, $x^{\mathrm{S}}{ }_{\mathrm{i}}$.

The Butler model may be criticized for its restriction to consider the surface as a phase of a single monolayer, neglecting concentration gradients perpendicular to the surface. On the other hand, as shown recently, [43], this phase does not necessarily need to be a mono-layer, as originally stated by Butler.

A different approach is followed by the Chatain model $[44,45]$ taking into account a concentration gradient as multiple layers, $n=1 \ldots k$, with different compositions, $x^{(\mathrm{n})}{ }_{\text {in }}$, in each layer, $n$. The atoms of the liquid are assumed to reside on cubic lattice sites with a coordination number, $z=12$, in the bulk, and a lateral coordination number, $z_{1}=6$. The number of neighboring atoms in an adjacent atom layer is, thus, $z_{\mathrm{v}}=3$. Interactions among atoms take place only with the nearest neighbors, where, $\Phi_{\mathrm{i}, \mathrm{j}}$ denotes a single bond energy for a bond 
163 between atomsi and $j$. With this parameter the regular solution constant, $\omega$, can be defined in

164 Ref. [43] as $\omega=\Phi_{\mathrm{Al}, \mathrm{Ti}}-0.5\left(\Phi_{\mathrm{Al}, \mathrm{Al}+} \Phi_{\mathrm{Ti}, \mathrm{Ti}}\right)$. Assuming further that $\gamma_{\mathrm{i}}=-\mathrm{Z}_{\mathrm{V}} \Phi_{\mathrm{i}, \mathrm{i}} / 2 \mathrm{~A}$, the following

165 expression is obtained for the surface free energy of a regular solution [43]:

$$
\begin{aligned}
& A \gamma=A \gamma_{\mathrm{Al}} x_{\mathrm{Al}}^{(1)}+A \gamma_{\mathrm{Ti}} x_{\mathrm{Ti}}^{(1)} \\
& -z_{\mathrm{v}} \omega\left(x_{\mathrm{Ti}}^{(1)}-2 x_{\mathrm{Ti}}^{\mathrm{B}} x_{\mathrm{Ti}}^{(1)}-\left(x_{\mathrm{Ti}}^{\mathrm{B}}\right)^{2}\right)-z_{\mathrm{v}} \omega \sum_{n=1}^{k}\left(x_{\mathrm{Ti}}^{(\mathrm{n})}-x_{\mathrm{Ti}}^{\mathrm{B}}\right)\left(x_{\mathrm{Al}}^{(\mathrm{n})}-x_{\mathrm{Al}}^{\mathrm{B}}\right) \\
& -z_{\mathrm{l}} \omega \sum_{n=1}^{k}\left(x_{\mathrm{Ti}}^{(\mathrm{n})}-x_{\mathrm{Ti}}^{\mathrm{B}}\right)^{2} \\
& +R T \sum_{n=1}^{k}\left[x_{\mathrm{Ti}}^{(\mathrm{n})} \ln \left(\frac{x_{\mathrm{Ti}}^{(\mathrm{n})}}{x_{\mathrm{Ti}}^{\mathrm{B}}}\right)+x_{\mathrm{Al}}^{(\mathrm{n})} \ln \left(\frac{x_{\mathrm{Al}}^{(\mathrm{n})}}{x_{\mathrm{Al}}^{\mathrm{B}}}\right)\right]
\end{aligned}
$$

166 The parameters $\Phi_{\mathrm{i}, \mathrm{i}}$ and $\omega$ are related to the surface tension and the excess free energy,

167 respectively, as follows:

$\Phi_{i, \mathrm{i}}=-A \gamma_{\mathrm{i}}$

168 And

$\omega=-\frac{T^{2}}{Z \cdot x_{\mathrm{Al}}^{\mathrm{B}} x_{\mathrm{Ti}}^{\mathrm{B}}} \frac{\partial}{\partial T}\left(\frac{{ }^{\mathrm{E}} G(T)}{T}\right)$

169 The excess free energy, ${ }^{\mathrm{E}} G$, used in Eqs. (8) and (10) is parametrized by a Redlich-Kister

170 polynomial, as a function of concentration and temperature, with ${ }^{v} L_{\mathrm{Al}, \mathrm{Ti}}(T)$ being temperature

171 dependent interaction parameters:

${ }^{\mathrm{E}} G\left(T, x_{\mathrm{Al}}, x_{\mathrm{Ti}}\right)=x_{\mathrm{Al}} x_{\mathrm{Ti}} \sum_{v=0}^{v} L_{\mathrm{Al}, \mathrm{Ti}}(T)\left(x_{\mathrm{Al}}-x_{\mathrm{Ti}}\right)^{v}$

172 For a binary ideal solution, ${ }^{\mathrm{E}} G=0$, the following expressing is obtained for its surface tension

$173 \gamma^{\text {jdeal }}[46]$ :

$\gamma^{\text {ideal }}(T)=x_{\mathrm{Al}}^{\mathrm{S}} \gamma_{\mathrm{Al}}(T)+x_{\mathrm{Ti}}^{\mathrm{S}} \gamma_{\mathrm{Ti}}(T)$

174 The deviation from the ideal surface tension, $\gamma^{\text {ideal }}$, is called excess surface tension, $\gamma^{\mathrm{E}}$ as:

$\gamma=\gamma^{\text {ideal }}+\gamma^{\mathrm{E}}$ 
175 With this formalism, similar that one for the excess molar volume in section $1.2, \gamma^{E}$ may also

176 be fitted analogously to a second order Redlich-Kister polynomial, with ${ }^{v} u(T)$ being

177 temperature-dependent interaction parameters:

$\gamma^{\mathrm{E}}=x_{\mathrm{Al}}^{\mathrm{B}} x_{\mathrm{Ti}}^{\mathrm{B}}\left(\sum_{v=0}^{\mathrm{N}} v u(T)\left(x_{\mathrm{Al}}^{\mathrm{B}}-x_{\mathrm{Ti}}^{\mathrm{B}}\right)^{v}\right)$

178

179

\section{Experimental}

180

Density and surface tension measurements are conducted in an electromagnetic levitation

chamber described in detail in Ref. [47]. Typically, the alloy samples have diameters of $3 \mathrm{~mm}$

and masses of approximately $0.5 \mathrm{~g}$. Inside the chamber the samples are positioned and melted

by a spatially inhomogeneous electromagnetic field. This field is generated by a coil to which an alternating current of $100 \mathrm{~A}$ is applied with a frequency of approximately $250 \mathrm{kHz}$.

185

Processing takes place under protective inert gas mixtures of He and Ar (both having a purity of $99.9999 \%)$. Since, for electromagnetic levitation, positioning and heating are not generally decoupled, additional temperature control is provided by an adjustable cooling flow of inert gas, admitted to the samples via a nozzle.

189 The sample temperature, $T$, is measured using an infrared pyrometer directed to the specimen

190 from the side. As the effective emissivity is not known in general, the pyrometer signal, $T_{\mathrm{P}}$,

191 needs to be recalibrated with respect to the known liquidus temperature, $T_{\mathrm{L}}$, and the apparent

192 liquidus temperature, $T_{\mathrm{L}, \mathrm{P}}$. The apparent liquidus temperature is identified during the

193 measurement by a kink in the pyrometer signal that appears, when the melting process is

194 completed. The recalibration is accomplished using the following relation derived from

195 Wien's law [48]:

$\frac{1}{T}-\frac{1}{T_{\mathrm{P}}}=\frac{1}{T_{\mathrm{L}}}-\frac{1}{T_{\mathrm{L}, \mathrm{P}}}$

196 For metallic liquids, Eq. (17) gives a good approximation for the temperature, provided that the sample emissivity at the operating wavelength remains constant over the investigated 
198

199

temperature interval [49]. For the pure elements and alloys, values of $T_{\mathrm{L}}$ are are shown in Tables 2, 3, 4 and 5 and taken from Ref. [50], using the CALPHAD approach to evaluate thermodynamic data. We have chosen the data as the used model is taking into account recent experimental data and is in close agreement with these data [50]. The phase diagram of the binary system of Al-Ti is shown in Fig. 1, respectively.

The preparation of the specific samples is performed by arc-melting the corresponding amounts of $\mathrm{Al}(99.999 \%)$ and $\mathrm{Ti}(99.99 \%)$. An ultrasound bath in propanol is used for cleaning and the removal of scales.

Finally, all samples are briefly heated up to a temperature of at least $T_{\mathrm{L}}+100 \mathrm{~K}$. This produces further purification through evaporation of volatile Al-oxides.

The large difference in the melting temperatures of Al, $933 \mathrm{~K}\left(660^{\circ} \mathrm{C}\right)$, and $\mathrm{Ti}, 1941 \mathrm{~K}(1668$ ${ }^{\circ} \mathrm{C}$ ), presents a challenge for the processing of the liquid alloys, due to the partially intense evaporation of Al. This may cause a shift in the sample mass and its composition. These effects may limit the accuracy of both density and surface tension data. Therefore, the mass loss of each sample is evaluated after each measurement and, in the event that it exceeds 0.1 $\%$ of the initial sample mass, the results are dismissed.

\subsection{Density}

The optical dilatometry method $[30,47,51]$ is used to measure density and molar volume. This method employs lateral shadow images of the sample captured by a digital charge-coupled device (CCD) camera. The images are analyzed by an edge detection algorithm that determines the radius, $R d$, with respect to the drop center and the azimuthal angle $\varphi$. The obtained curve, $R d(\varphi)$, is averaged over 1000 frames in order to eliminate the influence of surface oscillations, and is then fitted by Legendre polynomials of order $\leq 6$, where the brackets <..> denote averaging: 
$\langle R d(\varphi)\rangle=\sum_{l=0}^{6} a_{1} P_{1}(\cos (\varphi))$

223 In Eq. (18), $P_{\mathrm{i}}$ is the $l$-th Legendre polynomial, and $a_{\mathrm{l}}$ are coefficients determined by the fit.

224 The volume is calculated as following, assuming axial symmetry [30] of the droplet in

225 mechanical equilibrium:

$V_{\mathrm{P}}=\frac{2}{3} \pi \int_{0}^{\pi}\langle R d(\varphi)\rangle^{3} \sin (\varphi) d \varphi$

226 Here, $V_{\mathrm{P}}$ denotes the volume in pixel units. The real droplet volume, ${ }^{\text {drop }} V$, is related to the

227 pixel volume, $V_{\mathrm{P}}$, by a scaling factor, $q$ with ${ }^{\text {drop }} V=q V_{\mathrm{P}} . \quad q$ is obtained by a calibration

228 procedure described in Ref. [28q]. Finally, the density is calculated with respect to the sample

229 mass, $M$, by $\rho=M /{ }^{\text {drop }} V$. Following this procedure the obtained results are accurate within

$230 \Delta \rho / \rho \leq \pm 1.0 \%[24,30]$.

231

232

\subsection{Surface tension}

233 The oscillating droplet method [47] is applied to determine surface tension. In this method

234 spontaneously self-excited surface oscillations are observed by means of a digital

complementary metal oxide semiconductor (CMOS)-camera directed at the sample from

above. The camera has a pixel resolution of 400x400, and operates at a frequency of $400 \mathrm{~Hz}$.

237 A series of $2^{n}=4196$ frames is recorded for each investigated temperature and, these are

238 then analyzed afterwards with dedicated software that determines the frequency spectra of the

239 sample radii, $R$, from the image sequences. Under terrestrial conditions i.e. in the case of a

240 non-spherical and slightly rotating droplet the spectrum consists of five distinguished peaks,

241 at frequencies $\omega_{\mathrm{m}}$, corresponding to the surface oscillation modes, with $m$ being a quantum

242 number from, in this case, -2 to +2 [47]. Additionally, the three translational frequencies

$243 \omega_{\mathrm{X}}, \omega_{\mathrm{Y}}, \omega_{\mathrm{Z}}$, can be identified from the motion of the droplets' centers of gravity, and thus

244 the mean quadratic translational frequency can be calculated as:

$\Omega^{2}=\frac{1}{3}\left(\omega_{\mathrm{X}}^{2}+\omega_{\mathrm{Y}}^{2}+\omega_{\mathrm{Z}}^{2}\right)$ 
245 From the five surface oscillations and three translational frequencies, the surface tension, $\gamma$, is 246 determined using the sum formula of Cummings and Blackburn [51], where $g$ denotes the 247 gravitational acceleration and $R_{0}$ the radius of the sample, which is assumed to be spherical:

$\gamma=\frac{3 M}{160 \pi} \sum_{m=-2}^{+2} \omega_{\mathrm{m}}^{2}-1.9 \Omega^{2}-0.3\left(\frac{g}{R_{0}}\right)^{2} \Omega^{-2}$

248 This procedure allows the precise determination of the surface tension within a margin of $\Delta \gamma / \gamma$

$249 \leq 5.0 \%[24]$

250

251

\section{Results}

252

\subsection{Density}

253 Measured density data are plotted in Fig. 2, versus temperature for liquid samples with Al254 mole fractions $x_{\mathrm{Al}}$, ranging from 0 to 100 at.-\%. Each measurement is carried out over a broad 255 temperature range, of 150-500 K, including up to $200 \mathrm{~K}$ undercooling below the 256 corresponding liquidus temperature. Generally, the temperature range is limited by the 257 nucleation of the solid phase at low temperatures and by mass loss due to evaporation at 258 sufficiently large temperatures.

259 For all compositions, the density, $\rho$, changes linearly with temperature and with a negative 260 slope, indicating a positive thermal volume expansion coefficient. Moreover, the density 261 changes gradually with $x_{\mathrm{Al}}^{\mathrm{B}}$. Pure Al exhibits the lowest density, and Ti the largest. The 262 density values of the alloys lie within these two extremes.

263 The experimentally obtained values of $\rho(T)$ can be fitted by Eq. (1) with the fits shown in Fig. 2642 by the solid lines. The obtained values of $\rho_{\mathrm{L}}$ and $\rho_{\mathrm{T}}$, as well as the volume expansion 265 coefficient, $\beta$, calculated from this data via Eq. (2), are listed along with in Tables 2, 3, and 6 266 along with the corresponding liquidus temperatures. Accordingly, Table 2 contains the results 267 for the pure elements and Table 3 contains the results for the alloys. 
In the case of pure $\mathrm{Al}$, the agreement among the values of $\rho_{\mathrm{L}}$ is around a mean value of 2.30 $\mathrm{gcm}^{-3}$, within $\pm 0.02 \mathrm{gcm}^{-3}$, corresponding to a relative uncertainty of $\pm 0.09 \%$. The values of $\rho_{\mathrm{T}}$ are distributed around a mean of $-2.18 \cdot 10^{-4} \mathrm{gcm}^{-3} \mathrm{~K}^{-1}$, within $\pm 0.32 \cdot 10^{-4} \mathrm{gcm}^{-3} \mathrm{~K}^{-1}$, corresponding to $\pm 15 \%$. In the case of $\mathrm{Ti}$, the average of the individual values of $\rho_{\mathrm{L}}$ amounts to $4.12( \pm 0.04) \mathrm{gcm}^{-3}$, corresponding to a relative deviation of $1 \%$. The temperature coefficient of pure Ti scatters around $-2.85( \pm 1.24) \cdot 10^{-4} \mathrm{gcm}^{-3} \mathrm{~K}^{-1}$ and, hence, within a relative margin of $35 \%$. Generally, it is observed for our measurements that the deviations in $\rho_{\mathrm{T}}$ are in the range of up to $50 \%$, as its precise determination is sensitive to the accuracy of the data points, determined at the margins of the temperature intervals. These are, however, the points that are most exposed to the impact of potential sources of error, such as evaporation at high temperatures, or possible oxide formation, for example at low temperatures.

Table 6 contains data for $\rho_{\mathrm{L}}$ and $\rho_{\mathrm{T}}$, and their mean values selected from literature [4, 3545,52]. In the case of pure Ti mean values of $4.17( \pm 0.07) \mathrm{gcm}^{-3}$, for $\rho_{\mathrm{L}}$ and $-4.18 \cdot 10^{-4}$

$281\left( \pm 3.02 \cdot 10^{-4}\right) \mathrm{gcm}^{-3} \mathrm{~K}^{-1}$, for $\rho_{\mathrm{T}}$ can be found. Thus, the data presented in the present work is in 282 good agreement with the literature and lies within the error for the mean value of pure Ti. Accordingly, for pure $\mathrm{Al}$ the mean value of the temperature coefficient of the present work, $2.85( \pm 1.24) \cdot 10^{-4} \mathrm{gcm}^{-3} \mathrm{~K}^{-1}$, agrees well with the mean temperature coefficient value of the 285 selected literature data of $-2.91( \pm 0.5) \cdot 10^{-4} \mathrm{gcm}^{-3} \mathrm{~K}^{-1}$. However, for the mean value of $\rho_{\mathrm{L}}$ for 286 pure Al, the value of the present work, $2.30( \pm 0.02) \mathrm{gcm}^{-3}$, is lower and lies beyond the errors 287 bars of the mean value, $2.36( \pm 0.03) \mathrm{gcm}^{-3}$, given by literature, see Tabs. 2 and 6 . The reason 288 is unclear.

289 In Table 3 the values of $\rho_{\mathrm{L}}$ change gradually with increasing $x_{\mathrm{Al}}^{\mathrm{B}}$. Except for $\mathrm{Al}_{40} \mathrm{Ti}_{60}, \mathrm{Al}_{60} \mathrm{Ti}_{40}$ 290 and $\mathrm{Al}_{90} \mathrm{Ti}_{10}$, all compositions are measured more than once, and, in these cases, the observed 291 scatter in $\rho_{\mathrm{L}}$ and $\rho_{\mathrm{T}}$ is in the same order of magnitude as for the pure elements. For $\rho_{\mathrm{T}}$ this 292 margin is about $40 \%$, which corresponds to the magnitude of the variation among the 
different values of $\rho_{\mathrm{T}}$ over all compositions. Hence, it is justified to claim that with respect to

294 the experimental accuracy of the data, $\rho_{\mathrm{T}}$ is basically constant with a mean value of -3.83

$295( \pm 1.6) \cdot 10^{-4} \mathrm{gcm}^{-3}$. The same holds for $\beta$, for which a mean value of $1.18( \pm 0.5) \cdot 10^{-4} \mathrm{~K}^{-1}$ is 296 found over all compositions.

297 In addition to $\rho_{\mathrm{L}}, \rho_{\mathrm{T}}$ and $\beta$, the Tables 6 and 7 also show the isothermal density calculated 298 from Eq. (1) at $T=1873 \mathrm{~K}\left(1600^{\circ} \mathrm{C}\right)$. This temperature is chosen to be in the middle of the 299 total range of temperatures covered by the experiments. As can be seen from the Tables, $300 \rho\left(T=1873 \mathrm{~K}\left(1600{ }^{\circ} \mathrm{C}\right)\right)$ decreases monotonically from $\rho_{\mathrm{Ti}}=4.14( \pm 0.04) \mathrm{gcm}^{-3}$ to $\rho_{\mathrm{Al}}=2.09$ $301 \quad( \pm 0.01) \mathrm{gcm}^{-3}$ upon increasing $x_{\mathrm{Al}}^{\mathrm{B}}$.

302 In order to elucidate and understand how the density changes with composition, it is indicated 303 not to discuss the mass density but rather the isothermal molar volume, $V$ and its composition 304 dependence. In contrast with mass density, the molar volume is an additive quantity.

305 Moreover, effects originating from the packing and ordering of atoms could be obscured by 306 the mass differences between the pure elements, $\mathrm{Al}$ and $\mathrm{Ti}$, if only the mass density is 307 considered.

308 For this reason, the molar volume at $1873 \mathrm{~K}(1600 \mathrm{~K})$ is plotted in Fig. 3 versus $x_{\mathrm{Al}}^{\mathrm{B}}$. For some 309 alloys this temperature lies outside the measured temperature range, due to the 310 aforementioned temperature range boundaries. For these alloys, the density is extrapolated by 311 Eq. (2). This is marked in Fig. 3 by hollow or semi-hollow symbols. The precise location of 312 the phase boundaries is not crucial in this context, as the properties of the stable (or 313 metastable) liquid are of primary interest.

314 As can be seen from Fig. 3, the molar volume, $V$, generally increases with an increasing mole 315 fraction of respective mean values of the pure elements, $x_{\mathrm{Al}}^{\mathrm{B}}$, from $11.54 \mathrm{~cm}^{3} \mathrm{~mol}^{-1}$ to 12.92 $316 \mathrm{~cm}^{3} \mathrm{~mol}^{-1}$. 
Starting on the left side in Fig. 3, there seems to the tendency that $V$ slightly decreases for

$318 x_{\mathrm{Al}}^{\mathrm{B}}<40$ at.-\%. However, this tendency is beyond the scatter of the experimental data.

319 Therefore, $V$ can be regarded as practically constant at $\approx 11.5 \mathrm{~cm}^{3} \mathrm{~mol}^{-1}$ for $x_{\mathrm{Al}}^{\mathrm{B}}<70$ at.-\%. For $320 \quad x_{\mathrm{Al}}^{\mathrm{B}} \geq 70$ at.-\%, however, $V$ steeply increases with $x_{\mathrm{Al}}^{\mathrm{B}}$ until its final value is reached at $321 \quad x_{\mathrm{Al}}^{\mathrm{B}}=100$ at. $-\%$.

\subsection{Surface tension}

324 Surface tension data of the liquid pure elements is plotted versus temperature in Fig. 4 for $\mathrm{Al}$ 325 and in Fig. 5 for Ti. In the case of Al, the data shown is published by us previously [24,33]. 326 The experimentally obtained values of $\gamma(T)$ follow linear laws and hence, can be fitted by Eq. 327 (7).

328 In the case of pure Ti, the solid squares shown in Fig. 5 represent three individual 329 measurements which are combined to a single curve. For each of these measurements, the 330 obtained fit parameters $\gamma_{\mathrm{L}}$ and $\gamma_{\mathrm{T}}$ are shown in Table 4. From these, arithmetic averages are 331 formed which are shown in Tab. 4 as well, and additionally, in Tab 8. The mean of $\gamma_{\mathrm{L}}$ amounts to $1.56( \pm 0.02) \mathrm{Nm}^{-1}$. Its’ uncertainty corresponds to a relative deviation of $\pm 1.3 \%$.

333 The temperature coefficient of pure Ti scatters around $(-1.65( \pm 0.95)) \cdot 10^{-4} \mathrm{Nm}^{-1} \mathrm{~K}^{-1}$, and hence, within a relative margin of $\pm 58 \%$. Generally, it is observed that the deviations in $\gamma_{\top}$ are in the range of up to $58 \%$, which is larger than the deviations in the surface tension, $\gamma$. This is for essentially the same reasons as the increased scatter in $\rho_{\text {T. }}$ For comparison, Fig. 5 and Tab. 8 also show surface tension data of liquid $\mathrm{Ti}$, or their linear representations, as obtained in

338 literature. Excellent agreement is obviously obtained with the data published by Paradis [53] 339 who measured $\gamma$ in electrostatic levitation.

340 Fig. 4 shows two sets of experimental surface tension data of liquid Al. The hollow circles 341 represent data that has been measured by Kolland [35] whereas no particular attention was 
paid to the oxygen partial pressure. It has been concluded in Ref. [35] that this result corresponds to a case where the surface contains a significant amount of dissolved oxygen.

344 Fitting Eq. (7) to this data yields $\gamma_{\mathrm{L}}=0.87 \mathrm{Nm}^{-1}$ and $\gamma_{\mathrm{T}}=-1.46 \cdot 10^{-4} \mathrm{Nm}^{-1} \mathrm{~K}^{-1}$. This is roughly $5 \%$ 345 larger than data reported by Molina [54] for an oxygen saturated liquid surface, see Fig. 4.

346 The solid squares in Fig. 4 represent the measurement of Kobatake [37] where the oxygen 347 partial pressure was controlled $\left(10^{-1} \mathrm{~Pa}\right)$ using an oxygen sensing and control system (OSC).

348 The obtained curve is in good agreement with the results of Molina who presented in his 349 study [54] also surface tension data for an oxygen free Al surface. In Fig. 4, the results of 350 Kobatake even overestimate the data of Molina slightly. Fitting Eq. (7) to the data of 351 Kobatake [37] yields $\gamma_{\mathrm{L}}=0.98 \mathrm{Nm}^{-1}$ and $\gamma_{\mathrm{T}}=-2.71 \cdot 10^{-4} \mathrm{Nm}^{-1} \mathrm{~K}^{-1}$. For Al, the parameters $\gamma_{\mathrm{L}}$ and $352 \gamma_{\mathrm{T}}$ are listed in Table 4. Detailed discussions of the surface tension of liquid $\mathrm{Al}$ are further 353 presented in refs. [35,37].

354 Figure 6 shows plots of $\gamma$ versus temperature for the liquid alloy samples. For the sake of completeness and in order to be able to make visual comparisons, the figure also shows the data for pure $\mathrm{Ti}$ and representations of the data of pure $\mathrm{Al}$ taken from refs. [35,37]. The Al-mole fraction, $x_{\mathrm{Al}}^{\mathrm{B}}$, ranges from 0 to 100 at.-\% in Fig. 6. Each measurement is carried out over a broad temperature range of 100-250 K, including up to $200 \mathrm{~K}$ undercooling below the corresponding liquidus temperature. Corresponding to the density, surface tension measurements are restricted by the same temperature range boundaries.

361 For all compositions it is found again that $\gamma$ linearly declines with temperature. Moreover, $\gamma$ changes gradually with $x_{\mathrm{Al}}^{\mathrm{B}}$, and exhibits an increase from the lowest values for pure $\mathrm{Al}$, to 363 the highest $\gamma$ for pure Ti.

364 The individual fits of Eq. (7) are shown in Fig. 6 by the solid lines. The obtained values of $\gamma_{\mathrm{L}}$ 365 and $\gamma_{T}$ are listed in Tab. 5 for the alloy system, together with the corresponding liquidus temperatures $T_{\mathrm{L}}$. 
As shown in Tab. 5, the values of $\gamma_{\mathrm{L}}$ change gradually with increasing $x_{\mathrm{Al}}^{\mathrm{B}}$. For multiple data of the same alloys, the observed scatter for $\gamma_{\mathrm{L}}$ and $\gamma_{T}$ ranges in the same order of magnitude as for the pure elements. In particular, for $\gamma_{\mathrm{T}}$, the margin for all compositions is around $55 \%$. That agrees well with the magnitude of variation among the $\gamma_{\mathrm{T}}$ data of each compositions of 20-60 \%. Hence, it is justified to claim that, with respect to the experimental accuracy of the data, $\gamma_{\mathrm{T}}$ is essentially constant, with a mean value of $(-2.51( \pm 1.37)) \cdot 10^{-4} \mathrm{Nm}^{-1} \mathrm{~K}^{-1}$. In addition, Tables 4 and 5 show the isothermal surface tension calculated from Eq. (7) at $T=1950 \mathrm{~K}\left(1677^{\circ} \mathrm{C}\right)$, chosen from the middle of the total range of temperatures covered by the experiments. As can be seen from the Tables, $\chi\left(T=1950 \mathrm{~K}\left(1677^{\circ} \mathrm{C}\right)\right)$ decreases monotonically from $\gamma_{\mathrm{Ti}}=1.56( \pm 0.02) \mathrm{Nm}^{-1}$ to $\gamma_{\mathrm{Al}}=0.71( \pm 0.01) \mathrm{Nm}^{-1}$ upon increasing $x_{\mathrm{Al}}^{\mathrm{B}}$. In Fig. 7 the surface tension at $T=1950 \mathrm{~K}\left(1677^{\circ} \mathrm{C}\right)$ is plotted versus $x_{\mathrm{Al}}^{\mathrm{B}}$. Analogously to the density data, the extrapolated value for $\chi\left(T=1950 \mathrm{~K}\left(1677^{\circ} \mathrm{C}\right)\right)$ partially outlies the measured temperature range for some alloys, which is negligible in the context. Starting on the left side in Fig. 7, $\chi\left(T=1950 \mathrm{~K}\left(1677^{\circ} \mathrm{C}\right)\right)$ decreases with concentration for component $x_{\mathrm{Al}}^{\mathrm{B}}<20$ at.-\%. There appears to be the tendency that $\chi\left(T=1950 \mathrm{~K}\left(1677^{\circ} \mathrm{C}\right)\right)$ does not decrease, and is approximately constant for 20 at.- $\% . \leq x_{\mathrm{Al}}^{\mathrm{B}} \leq 30$ at.- $\%$. However, this tendency is beyond the scatter of the experimental data. For $x_{\mathrm{Al}}^{\mathrm{B}}>30$ at.-\%, $\chi\left(T=1950 \mathrm{~K}\left(1677^{\circ} \mathrm{C}\right)\right)$ steeply decreases with $x_{\mathrm{Al}}^{\mathrm{B}}$, and exhibits a concave shape until its final value is reached at $x_{\mathrm{Al}}^{\mathrm{B}}=100$ at.-\%.

\section{Discussion}

\subsection{Density}

In addition to the experimental data, the calculated ideal molar volumes, $V^{\text {ideal }}$, at $T=1873 \mathrm{~K}$ $\left(1600^{\circ} \mathrm{C}\right)$, are plotted versus the bulk Al concentration in Fig. 3. Accordingly, the molar volumes of the pure components used for the calculation are assessed from the averaged density values at $T=1950 \mathrm{~K}$, with $\rho_{\mathrm{Al}}=2.09 \mathrm{gcm}^{-3}$ and $\rho_{\mathrm{Ti}}=4.14 \mathrm{gcm}^{-3}$. The deviation 
392 between the measured molar volume, $V$, and the ideal molar volume, $V^{\text {ideal }}$, corresponds to the 393 excess molar volume, $V^{E}$ Eq. (4). In Fig. 3, $V\left(x_{\mathrm{Al}}^{\mathrm{B}}\right)$ is fitted by a Redlich-Kister polynomial of 394 zeroth $(\mathrm{N}=0)$ and first $(\mathrm{N}=1)$ order. The fitted, temperature-dependent excess parameters, $395{ }^{0}$ Vand ${ }^{1} V$, are listed in Tab. 7. Regarding $V^{\text {ideal }}$ and $V$, the fits exhibit a negative deviation, and 396 hence, the excess volume is negative. For a fitted excess molar volume with $\mathrm{N}=0$ in Eq. (4), 397 the molar volume shows a concave shape, with the maximum negative excess molar volume 398 for an Al concentration, $x_{\mathrm{Al}}^{\mathrm{B}} \approx 20$ at.-\% of around $-0.3710^{-6} \mathrm{~m}^{3} \mathrm{~mol}^{-1}$. Starting from the left 399 side for a fit with $\mathrm{N}=0$ in Eq. (4), $V$ slightly increases for $x_{\mathrm{Al}}^{\mathrm{B}}<16$ at.-\%, and shows a minor 400 local maximum at $x_{\mathrm{Al}}^{\mathrm{B}}=16$ at.-\%. For 16 at.-\% $<x_{\mathrm{Al}}^{\mathrm{B}}<67$ at.-\%, $V$ slightly decreases with a 401 maximum negative excess molar volume, $V^{\mathrm{E}} \approx-0.810^{-6} \mathrm{~m}^{3} \mathrm{~mol}^{-1}$, for $x_{\mathrm{Al}}^{\mathrm{B}}=67 \mathrm{at} .-\%$. For $x_{\mathrm{Al}}^{\mathrm{B}} \geq$ 402 67 at.-\%, $V$ steeply increases with increasing $\mathrm{Al}$ concentration, until its final value is reached 403 at $x_{\mathrm{Al}}^{\mathrm{B}}=100$ at.-\%. In contrast to $V^{\mathrm{i}}$, both fits are in good agreement with the data.

404 Consequently, it can be said that, referring to the density and molar volume, Al-Ti is a highly 405 nonideal system, showing significant negative excess volumes.

406 However, the fit of first order reproduces the data and its trend more accurately. Thus, we 407 suggest, in the case of binary Al-Ti, two fit parameters, ${ }^{0} V$ and ${ }^{1} V$, are needed to describe the 408 excess molar volume. This is in accordance with other binary Ti-containing systems, where 409 two fit parameters are used to fit the data qualitatively and quantitatively well; for example, in 410 the case of $\mathrm{Cu}-\mathrm{Ti}[26,27]$. However, a positive excess volume has been found in the case of $411 \mathrm{Cu}$-Ti. Negative excess molar volumes have been found in other Al-containing systems such as Al-Fe [28], Al-Ag [30], Al-Cu [20] and Al-Ni [28], hence, the results are in good agreement with literature data, for example, with the investigations by Peng et al. for the Al-

414 Au system [34]. Density measurements and molecular dynamics (MD) simulations in that 415 system suggest that the nonideal mixing behavior occurs due to the apparent decreasing atomic radii of the $\mathrm{Al}$ atoms. This leads to a shrunken close packing, especially of the $\mathrm{Al}-\mathrm{Al}$ 
pairs [34]. Taking this into account, similar processes in the Al-Ti system are likely, but

418 further investigations, e.g. MD simulations, experiments with neutron or X-ray scattering are required to confirm this.

420 Fig. 8 shows plotted and fitted isothermal excess molar volumes, $V^{\mathrm{E}}$, as a function of the Al

421 concentration, $x_{\mathrm{Al}}^{\mathrm{B}}$, for different temperatures $\left(T=1473 \mathrm{~K}\left(1200^{\circ} \mathrm{C}\right), 1673 \mathrm{~K}\left(1400^{\circ} \mathrm{C}\right)\right.$, and

$\left.4221873 \mathrm{~K}\left(1600^{\circ} \mathrm{C}\right)\right)$. Corresponding to its definition, the excess molar volume for the pure

423 elements $\mathrm{Al}$ and Ti equals zero. For all temperatures, the values show a concave shape.

424 Starting from the left side, $V^{\mathrm{E}}$ decreases until its maximum negative values of around $V^{\mathrm{E}} \approx$ -

$425 \quad 0.80-1.0510^{-6} \mathrm{~m}^{3} \mathrm{~mol}^{-1}$ for $x_{\mathrm{Al}}^{\mathrm{B}} \approx 60-70$ at.-\%. Accordingly, the maximum negative excess

426 molar volumes decrease with increasing temperatures, while their values also shift to higher

427 Al concentrations. This shift indicates, that a more efficient packing and interaction occur for

428 lower temperatures, as pronounced atomic mobility and dynamics at higher temperatures

429 suppress those interactions and entropy becomes dominant.

\subsection{The role of oxygen}

432 Due to high affinity of oxygen to both elements, $\mathrm{Al}$ and $\mathrm{Ti}$, the impact of potentially existing traces of oxygen on the surface tension needs to be discussed.

In the case of pure liquid $\mathrm{Al}$, the effect is demonstrated in Fig. 4. In the case of Kobatake’s

435 measurement, the oxygen partial pressure in the chamber $p^{\mathrm{Ch}}{ }_{\mathrm{O} 2}$ was adjusted at roughly $10^{-1}$

$436 \mathrm{~Pa}$. This is far above the equilibrium partial pressure, $10^{-25} \mathrm{~Pa}$, for $\mathrm{Al}_{2} \mathrm{O}_{3}$ formation [55].

437 However, it has been argued by Eustathopolous [56] that the evaporation of volatile $\mathrm{Al}_{2} \mathrm{O}$

438 effectively lowers the oxygen partial pressure $p^{S}{ }_{\mathrm{O} 2}$ in the vicinity of the surface. This can be

439 described by the following equation:

$440 \quad p_{\mathrm{O} 2}^{S}=\left\{\left(2 D_{\mathrm{O}} / D_{\mathrm{Ox}}\right) p^{\mathrm{Ch}}{ }_{\mathrm{O} 2} / K\right\}^{2} \approx\left(p^{\mathrm{Ch}}{ }_{\mathrm{O} 2} / K\right)^{2}$

441 where $K$ is the equilibrium constant of the reaction and $D_{\mathrm{O}}$ and $D_{\text {Ox }}$ indicate the diffusion

442 coefficients of oxygen and the oxide in the vapor, respectively. In the case of pure Al, the 
443 effective partial pressure of the sample, $p_{\mathrm{O} 2}^{S}$, can be estimated as $10^{-26} \mathrm{~Pa}$, which is well

444 below the equilibrium pressure and the surface tension measured by Kobatake for liquid $\mathrm{Al}$

445 can be regarded as reliable.

446 In the case of pure Ti, the situation is more complicated. A detailed thermodynamic analysis

447 on oxygen in liquid Ti performed by Belyanchikov [57] shows that there are no volatile

448 oxides in this system. Ti can reduce liquid $\mathrm{Al}$ and consequently capture all oxygen from $\mathrm{Al}$ if,

449 as in the present work, liquid Al-Ti is investigated. Belyanchikov [57] furthermore showed

450 that Ti can practically not be reduced by any of the strongest deoxidizers known, i.e. Ba, Be,

451 Ca, Ce, Hf, La, Mg, Sr, Zr, and Fe. The oxygen content of one of the solidified Ti samples

452 was determined in a LECO analysis after the levitation run. It was found that its oxygen

453 concentration was approx. $0.15 \%$. This value agrees with the maximum solubility of oxygen

454 in liquid Ti predicted by Belyanchikov [57] under the assumption that $\mathrm{Ti}$ is in contact with an 455 oxide.

456 On the other hand, Paradis argued in his work that his surface tension data on pure and 457 oxygen-free liquid Ti should be correct, because pronounced evaporation of liquid Ti might 458 induce a self-purification process of the sample [53]. It is evident that both datasets of the 459 surface tension of liquid $\mathrm{Ti}$, the one of Paradis and of the present work, belong to the highest 460 values obtained in Fig. 5. Most of the other data, including the one measured by Amore [27], 461 are lower. This fact indicates that oxygen, if dissolved in the liquid Ti samples, does not play 462 a significant role in the case of the present work.

\subsection{Surface tension}

465 A comparison of the experimental data and model calculations for the isothermal surface 466 tension, $\gamma\left(T=1950 \mathrm{~K}\left(1677^{\circ} \mathrm{C}\right)\right)$, is shown in Fig. 7. The data are fitted by a Redlich-Kister 467 type polynomial of first $(\mathrm{N}=1)$ order. The corresponding fit parameters, ${ }^{0} u(T=1950 \mathrm{~K}(1677$ $\left.468{ }^{\circ} \mathrm{C}\right)$ ) and ${ }^{1} u\left(T=1950 \mathrm{~K}\left(1677^{\circ} \mathrm{C}\right)\right)$, for the excess surface tension of the measured data are 
listed in Tab. 7. The fit is in good agreement with the data and lies within the error bars for all

$470 \mathrm{Al}$ concentrations. Generally, the fit follows the curvature of the data, except for 10 at.-\% <

$471 \quad x_{\mathrm{Al}}^{\mathrm{B}}<30$ at.-\%, where it does not reproduce the kink, and slightly overestimates the surface

472 tension.

473 The model for an ideal solution, following Eq. (15), exhibits a concave shape, with its highest

474 values for pure $\mathrm{Ti}$ and lowest values for pure Al. The model does not reproduce the data

475 qualitatively, and underestimates the values for all alloys except for $\mathrm{Al}_{90} \mathrm{Ti}_{10}$. Hence, the

476 model fails to describe the data correctly and Al-Ti does not show ideal solution behaviour,

477 analogously to density, excess free energy and other Al- and Ti-based alloys.

478 A far better agreement is obtained for the calculations by the Butler model, Eq. (9) with the

479 temperature dependent interaction parameters, ${ }^{v} L_{\mathrm{Al}, \mathrm{Ti}}(T)$, listed in Tab. 7 and Chatain model

$480[44,45]$ for subregular nonideal solutions. The surface tension and its concentration

481 dependence are predicted qualitatively with both models, showing positive excess values,

482 regarding the ideal solution. The Butler model shows a good agreement, in particular for 25

483 at.- $\% \geq x_{\mathrm{Al}}^{\mathrm{B}} \geq 50$ at.-\%. In this interval the model follows the curvature of the data and lies

484 within all error bars. Nevertheless, for 25 at.- $\%<x_{\mathrm{Al}}^{\mathrm{B}}<50$ at.-\% the Butler model

485 underestimates the data by 5-16 \% and does not reproduce the kink, shown by the data for

486 those concentrations. On the other hand, the calculations of the Chatain model $[44,45]$

487 reproduce the kink for an $\mathrm{Al}$ concentration around 25-50 at.-\%, but overestimate $\gamma(T=1950 \mathrm{~K}$

$\left.488\left(1677^{\circ} \mathrm{C}\right)\right)$ for 40 at.-\% $<x_{\mathrm{Al}}^{\mathrm{B}}<70$ at.-\% by 5-12\%. Although the Chatain model lies within

489 the error bars for $\mathrm{Al}$ concentrations greater than 70 at.-\%, the model predicts a negative kink

490 in this interval, while the data follows a minor a positive kink.

491 Overall, it is suggested that the Butler model for nonideal solutions reproduces the data most

492 accurately in the Al-Ti system. Usually, the ideal solution fails to predict experimental data

493 correctly, as for most systems, the excess free energy, ${ }^{\mathrm{E}} \mathrm{G} \neq 0$. For ideal solutions only the

494 surface segregation of the surface active component is taken into account e.g. Al in the case of 
Al-Ti but other inter-atomic effects are neglected. Surface segregation can be understood as a process of energy minimization, in order to minimize the energy of the system, $G_{\text {tot }}$, the component with the smaller surface tension becomes enriched in the surface layer. For alloys with ${ }^{\mathrm{E}} \mathrm{G}>0$, the surface segregation becomes enhanced, while for alloys with ${ }^{\mathrm{E}} \mathrm{G}<0$, the surface segregation of $\mathrm{Al}$ is suppressed, due to interatomic attractions. The latter is found for many $\mathrm{Al}$-systems, such as $\mathrm{Al}-\mathrm{Cu}, \mathrm{Al}-\mathrm{Ni}, \mathrm{Al}-\mathrm{Fe}$ and $\mathrm{Al}-\mathrm{Au}$, as reported by Brillo et al. [24], and leads to an increased surface tension, compared to the ideal system, as in the case of AlTi. The suppressed Al surface segregation of the nonideal solution, in comparison with the ideal solution is also calculated with the Butler model [39] for a monolayer, and the Chatain model $[44,45]$ for multiple layers, displayed in Fig. 9. Here, the Al-content of the surface is plotted against the Al-content of the bulk. For all models a general $\mathrm{Al}$ segregation is evident in an enriched $\mathrm{Al}$-content in the surface versus the bulk. Compared to the ideal solution, for $x_{\mathrm{Al}}^{\mathrm{B}} \leq$ 60 at.-\% the concentration of the top layer is relatively depleted by $\mathrm{Al}$, by up to $40 \%$ for the Butler model and up to $60 \%$ for the Chatain model. For Al concentrations higher than 60 at.$\%$ for the Butler model, and 80 at.-\% for the Chatain model, no further suppression of the segregation is predicted by the models. enrichment and depletion for the uppermost layers. Fig. 10 shows the concentration, $x_{\mathrm{Al}}(n)$, of each layer plotted against the layer number, $n$, for $\mathrm{Al}_{50} \mathrm{Au}_{50}$, at $T=1700 \mathrm{~K}\left(1427^{\circ} \mathrm{C}\right), T=1950$ $\mathrm{K}\left(1677^{\circ} \mathrm{C}\right)$. While, with respect to the bulk, the first layer exhibits an enrichment of $\mathrm{Al}$ of around $25 \%$, the second layer shows a depletion of $\mathrm{Al}$ of around $10 \%$. This oscillating behaviour continues for both temperatures in the figure, until, in the layer, $n=6$, the bulk composition is reached. Such concentration oscillations are called chemical layering. In this mechanism the segregation of one component to the surface leads to an excess of the other 520 component in the following layer. Due to the negative excess free energy, the other 
component is then favored in the second layer. Chemical layering has been observed in

522 several systems with negative excess free energy; for example in the cases of Al-Ni [29], Al-

$523 \mathrm{Cu}$ [31] and $\mathrm{Al}-\mathrm{Au}[35]$. For $T=1700 \mathrm{~K}\left(1427^{\circ} \mathrm{C}\right)$, the chemical layering is slightly more

524 pronounced than for $T=1950 \mathrm{~K}\left(1677^{\circ} \mathrm{C}\right)$, due to the minor atomic dynamics at low

525 temperatures and, thus, enhanced interactions between atoms.

526 The values for the temperature coefficient, $\gamma_{\mathrm{T}}$, experimentally obtained, and the values

527 calculated by the Chatain and Butler model, are plotted in Fig. 11. As $\gamma_{\mathrm{T}}$ was assumed to be

528 constant, with a mean value of $-2.51( \pm 1.37) 10^{-4} \cdot \mathrm{Nm}^{-1} \mathrm{~K}^{-1}$, the Butler model, with a mean

529 value of $-2.14( \pm 0.89) 10^{-4} \cdot \mathrm{Nm}^{-1} \mathrm{~K}^{-1}$, is, regarding the temperature coefficient, also in better

530 agreement with the data than the Chatain model with a mean value of $-1.50( \pm 0.21) 10^{-4} \cdot \mathrm{Nm}^{-}$

$531{ }^{1} \mathrm{~K}^{-1}$. Starting on the left side in Fig. 11, there appears to be the tendency for $\gamma_{\mathrm{T}}$ to slightly

532 decrease for $x_{\mathrm{Al}}^{\mathrm{B}}<40$ at.-\% and increases for higher $\mathrm{Al}$ concentrations, which corresponds to

533 the Butler model. However, this tendency is beyond the scatter of the experimental data.

534 The measured values and the values calculated from the Chatain and Butler model of the

535 excess surface tension, $\gamma^{\mathrm{E}}$, using Eq. (18), evaluated at a fixed temperature, $T=1950 \mathrm{~K}$ (1677

$536{ }^{\circ} \mathrm{C}$ ), are shown in Fig. 12. The corresponding fit parameters, ${ }^{0} u_{\mathrm{i}, \mathrm{j}}$ and ${ }^{1} u_{\mathrm{i}, \mathrm{j}}$, for the excess

537 surface tension of the measured data are listed in Tab. 7. The highest excess surface tension is

538 found for $x_{\mathrm{Al}}^{\mathrm{B}} \leq 40$ at.- $\%$, which amounts to $0.28 \mathrm{Nm}^{-1}$, while for higher Al concentrations the

539 excess surface tension is significantly smaller, at around $0.1 \mathrm{Nm}^{-1}$. As seen in Fig. 7, both

540 models are in good agreement with the surface tension, and the excess surface tension data,

541 respectively. The Butler model underestimates the data, especially for $x_{\mathrm{Al}}^{\mathrm{B}} \leq 40$ at.-\%, but

542 reproduces the data within the error bars. The Chatain model overestimates the data, except

543 for $x_{\mathrm{Al}}^{\mathrm{B}}>80$ at.-\%, and lies within the error bars, except for $x_{\mathrm{Al}}^{\mathrm{B}} \approx 50-60$ at.-\%. Qualitatively,

544 the Chatain model appears to reproduce the data more accurately for $x_{\mathrm{Al}}^{\mathrm{B}} \leq 40$ at.-\%, while

545 the Butler model appears more accurate for $x_{\mathrm{Al}}^{\mathrm{B}}>40$ at.- $\%$. The data and the Butler model 
could indicate that a pronounced suppression of $\mathrm{Al}$ segregation only occurs up to a certain $\mathrm{Al}$ concentration, of around 40 at.-\%.

548 In Fig. 13 the isothermal surface tension data of the binary Al-Ti system, at $T=1950 \mathrm{~K}$ (1677

$549{ }^{\circ} \mathrm{C}$ ), and literature surface data of pure Titanium and, some industrially used, multicomponent 550 alloys at equivalent temperatures, are plotted versus the $\mathrm{Al}$ concentration. As mentioned 551 above, multicomponent alloys on the basis of Al-Ti are of particular technical importance, 552 while data on their properties are sparse. As can be seen in Fig. 13, the surface tension data of 553 the binary system and the multicomponent alloys are in good agreement with deviations up to $55410 \%$, in the case of $\mathrm{Al}_{6} \mathrm{Ti}_{90} \mathrm{~V}_{4}$, reported by Egry et al. [59]. Those deviations lie within the 555 same range of order as the relative uncertainties for the data of the pure e.g. $8 \%$ for Ti, and 556 binary components e.g. $24 \%$ for $\mathrm{Al}_{80} \mathrm{Ti}_{20}$, reported by Novacovic et al. [25] and in the present 557 work. Therefore, the data that are presented in the present work do not only fill the database 558 for thermophysical properties of binary Al-Ti alloys, but also established a good starting point 559 for investigations and processing of industrially used Al-Ti-based alloys with multiple 560 components.

561 Oxygen adsorption at the surface of the sample can produce a reduction in the surface tension.

562 The electromagnetic levitation technique is a generally clean method which avoids contact 563 between the liquid alloy and a container. Although it does not avoid contact with the gas 564 phase, an oxygen-reduced sample surface can still be achieved as discussed above. For the 565 surface tension of pure Ti, no comparable results for measurements under oxygen reduced 566 atmosphere are available. Anyhow, the mean value of the surface tension value for pure Ti of 567 this work is higher than the mean value of the cited literature data. That indicates that our 568 measurements are averagely and comparatively less affected by oxygen impurities.

569 For future works an extend study on the dependence of the surface tension on the oxygen 570 partial pressure of Al-Ti alloys would be of great value and interest. Such a study is presently 571 being carried out by us. 


\section{Summary}

573 Density and surface tension of binary Al-Ti-alloys are measured over a broad temperature and

574

575

576

577

578

579

580

581

582

583

584

585

586

587

588

589

590

591

592

593

594

595

596

composition range. It is found that, for all compositions, the density and surface tensions

increase linearly upon decreasing temperatures. The data are analyzed concerning the

temperature coefficients, excess molar volume, excess surface tension and surface

segregation. Generally, Al-Ti is a highly nonideal system. Significantly highly negative

values are found for the excess molar volume, which is in good agreement with other binary

Ti-containing systems. Referring to the Al-Au system [34], shrunk Al radii are suggested to

mainly trigger that mechanism, but further investigations are needed to verify this hypothesis.

Concerning the surface tension, a highly nonideal behaviour could also be observed, with

positive values for the excess surface tension. The results correspond well with the predictions of the Butler [39] and the Chatain model [44, 45] for nonideal solutions with excess free energy, ${ }^{\mathrm{E}} \mathrm{G} \neq 0$. For nonideal solutions the models not only take the surface segregation of the surface active component, $\mathrm{Al}$, into account, but also the suppression of the latter, due to interatomic attractions. Both mechanisms can be distinguished in the Al-Ti-system, coinciding with other Al-systems, reported by Brillo [24].

Overall, the nonideal behaviour for all investigated properties of the Al-Ti-system is more distinct for relatively low temperatures, due to the minor atomic dynamics and thus, enhanced interactions between atoms.

Multicomponent Al-Ti-based alloys - rather than binary Al-Ti-alloys - are of primary interest for various high temperature applications; however data on their properties are sparse. Before investigating partly highly complicated multi-component systems, it is an useful if not necessary approach to start with measurement in the binary system. In this work we could show that the data of the binary and multiple component systems are in very good agreement (Fig. 13). Therefore, we suggest that the data of the binary Al-Ti-system, presented in this 
597 work, is not only interesting as fundamental research results, but may also be sufficient for

598 many applications with multi-component Al-Ti-alloys.

599 


\section{Acknowledgments}

601 This work has been supported by Professor Rainer Schmid-Fetzer, from TU-Clausthal,

602 Institute of Metallurgy, who calculated the respective liquidus temperatures of the binary Al-

603 Ti-system. The authors are grateful to Prof. Dr. Dieter Herlach for his critical review of this

604 study and for his valuable suggestions.

605 
606

607

608

609

610

611

612

613

614

615

616

617

618

619

620

621

622

623

624

625

626

627

628

629

630

631

\section{References}

[1] I. Egry, R. Brooks, D. Holland-Moritz, R. Novakovic, T. Matsushita, E. Ricci, S. Seetharaman, R. Wunderlich, D. Jarvis, Int. J. Thermophys. 2007 vol. 28, pp. 10261036

[2] Y.V. Naidich, Prog. Surf. Membr. Sci. 1981, vol. 14, pp. 353-484

[3] J.P. Garandet, B. Vinet, P. Gros, J. Colloid, Interf. Sci. 1994, vol. 165, pp, 351-354

[4] E. Gebhardt, M. Becker, S. Dorner, Aluminium 1955, vol. 31, pp. 315-321

[5] W. Coy, R. Mateer, Trans Amer. Soc. Metals, 1955, vol. 58, pp. 99 - 102

[6] E. Levin, G. Ayushina, P. Geld, High Temp. 1968, vol. 6 pp. 416-418

[7] A. Yatsenko,V. Kononenko, A. Sukhman, High Temp. 1972, vol. 10, pp. 55

[8] P. Smith, J. Elmer, G. Gallegos, Scripta Mat. 1999, vol. 40, pp. 937 - 941

[9] P. Nasch, S.G Steinemann, Phys. Chem. Liq. 1995, vol. 29, pp. 43-58

[10] K. Mills: Recommended values of thermophysical properties for selected commercial alloys. Woodhead, Cambridge, 2002.

[11] M. Assael, R. Banish, J. Brillo, I. Egry, R. Brooks, P. Quested, K. Mills, A. Nagashima, Y. Sato, W. Wakeham, J. Phys. Chem. Ref. Data, 2006, vol. 35, pp. 285-300

[12] T. Ishikawa, P. Paradis, J. Electron. Mater. 2005, vol. 34, pp. 1526-1532

[13] P. Paradis, T. Ishikawa, S. Yoda, Adv. Space Res. 2008, vol. 41, pp. 2118 - 2125

[14] G. Pottlacher: High Temperature Thermophysical Properties of 22 Pure Metals, Edition Keiper, Graz, 2009.

[15] V.P. Elyutin, M.A. Maurakh, Izv. A.N., O.T.N. (USSR) 1955, vol. 6, pp. 129-131.

[16] V. Arkhipkin, A. Agaev, G. Grigorev, V. Kostikov, Ind. Lab. 1973, vol. 39, pp. 1340

[17] T. Ishikawa, P. Paradis, T. Itami, S. Yoda, J. Chem. Phys. 2003, vol. 118, pp. 79127920

[18] B. Vinet, L. Magnusson, H. Fredriksson, P. Desre, J. Colloid Interface Sci. 2002, vol. 255, pp. 363-374 
632 [19] K. Man, Int. J. Thermophys. 2000, vol. 21, pp. 793-804

633 [20] J. Tiele, J. Kelly, Brit. J. Appl. Phys. 1963, vol. 14, pp. 717-719

634 [21] B. Allen, Trans. Metall. Soc. AIME 1963, vol. 227, pp. 1175-1183

635 [22] A.W. Peterson, H. Kedesdy, P.H. Keck, E. Schwarz, J. Appl. Phys. 1958, vol. 28, pp. $636 \quad 213-216$

637 [23] G. Kuppermann: The determination of the surface tension with the help of the levitated 638 reciprocating drop under terrestrial conditions and in space. Dissertation Technology $639 \quad$ University of Berlin, 2000.

640 [24] J. Brillo: Thermophysical properties of multicomponent liquid alloys, Walter de Gruyter 641 GmbH, Berlin/Boston, 2016.

642 [25] R. Novakovic, D. Giuranno, E. Ricci, A. Tuissi, R. Wunderlich, H.J. Fecht, I. Egry, 643 Appl. Surf. Sci. 2012, vol. 258, pp. 3269-3275

644 [26] S. Amore, S. Delsante, H. Kobatake, J. Brillo, J. Chem. Phys. 2013, vol. 139, p. 064504

645 [27] S. Amore, J. Brillo, R. Novakovic, I. Egry, Appl. Surf. Sci. 2011, vol. 257, pp. 7739$646 \quad 7745$.

647 [28] Y. Plevachuk, I. Egry, J. Brillo, D. Holland-Moritz, I. Kaban, Int J Mat Res. 2007, vol. $648 \quad 98$, pp. $107-111$

649 [29] I. Egry, J. Brillo, D. Holland-Moritz, Y. Plevachuk, Mat. Sci. Eng. 2008, vol. A 495, pp. $650 \quad 14-18$.

651 [30] J. Brillo, I. Egry, J. Westphal, Int. J. Mat. Res. 2008, vol. 99, pp. 162-167

652 [31] J. Schmitz, J. Brillo, I. Egry, R. Schmid-Fetzer, Int. J. Mat. Res. 2010, vol. 100, pp. $653 \quad 1529-1535$

654 [32] J. Brillo, R. Brooks, I. Egry, P. Quested, High Temp.-High Press. 2008, vol. 37, pp. $655 \quad 371-381$

656 [33] J. Brillo, Y. Plevachuk, I. Egry, J Mater Sci 2010, vol. 45, pp. 5150-5157 
657 [34] H.L. Peng, T. Voigtmann, G. Kolland, H. Kobatake, J. Brillo, Phys. Review 2015, vol. B 92, pp. 184201-1 - 184201-13

659

660

661

662

663

664

665

666

667

668

669

670

671

672

673

674

675

676

677

678

679

680

681

682

[35] J. Brillo, G. Kolland, J. Mat. Sci. 2016, vol. 51, pp. 4888-4901

[36] J. Schmitz, B. Hallstedt, J. Brillo, I. Egry, M. Schick, J. Mater. Sci. 2012, vol. 47, pp. $3706-3712$

[37] H. Kobatake, J. Brillo, J. Schmitz, P. Pichon, J. Mater. Sci. 2015, vol. 50, pp. 33513360

[38] H. Kobatake, J. Schmitz, J. Brillo. J. Mater. Sci. 2014, vol. 49, pp. 3541-3549

[39] J.A.V. Butler, Proc. R. Soc. 1932, vol. A135, pp. 348-374

[40] G. Kaptay, Calphad 2008, vol. 32, pp. 338-352

[41] T. Tanaka, T. Iida, Steel Res. 1994, vol. 65, pp. 21-28

[42] T. Tanaka, K. Hack, T. Iida, S. Hara, Z. Metallkd. 1996, vol. 87, pp. 380-389

[43] G. Kaptay, Langmuir 2015, vol. 31, pp. 5796-5804

[44] P. Wynblatt, A. Saul, D. Chatain, Acta Mater 1998, vol. 46, pp. 2337-2347

[45] C. Antion, D. Chatain, Surf. Sci. 2007, vol. 10, pp. 2232-2244

[46] I. Egry, J. Brillo, High Temperatures - High pressures 2013, vol. 42, pp. 59-68

[47] J. Brillo, G. Lohöfer, F. Schmidt-Hohagen, S. Schneider, I. Egry, Int. J. Materials and Product Technology 2006, vol. 26, pp. 247-273

[48] W. Wien, Philos. Magaz. 1897, vol. 5, pp. 214-220

[49] S. Krishnan, G.P. Hansen, R.H. Hauge, J.L. Margrave, High Temp. Sci. 1990, vol. 29, pp. 17- 52

[50] V. Witusiewicz, A.A. Bondar, U. Hecht, S. Rex, T. Velikanova, J. All. and Comp. 2008, vol. 465, pp. 64-77

[51] J. Brillo, I. Egry, Int. J. Thermophys. 2003, vol. 24, pp. 1155-1170.

[52] D.L. Cummings, D.A. Blackburn, J. Fluid Mech. 1991, vol. 224, pp. 395-416

[53] P. Paradis, W.K. Rhim, J. Chem. Thermodynamics 2000, vol. 32, pp. 123-133 
683 [54] JM. Molina, R. Voytovych, E. Louis, N. Eustathopoulos, Int J Adh Adhesives 2007, 684 vol. 27, pp. 394-401

685 [55] H. Ellingham, J. Soc. Chem. Ind. 1944, vol. 63, pp. 125 - 133

686 [56] N. Eustathopoulos, B. Drevet, J Crys Growth 2013, vol. 371, pp. 77-83

687 [57] L. N. Belyanchikov, Elektrometallurgiya 2009, vol. 11, pp. 25-32

688 [58] M.W. Chase, C.A. Davies, J.R. Downey, D.J. Furip, R.A. McDonald, A.N. Syverud, J. 689 Phys. Chem. Ref. Data 1985, vol. 14, Suppl 1, pp. 1-1856

690 [59] I. Egry, D. Holland-Moritz, R. Novakovic, E. Ricci, R. Wunderlich, N. Sobczak, Int. J. 691 Thermophys. 2010, vol. 31, pp. 949-965

692 [60] R. Nowak, T. Lanata, N. Sobczak, E. Ricci, D. Giuranno, R. Novakovic, D. Holland693 Moritz, I. Egry, J. Mater. Sci. 2010, vol. 45, pp. 1993-2001 
695

696 Fig. 1: Scheme of the phase diagram of Al-Ti according to the thermodynamic description of 697 Witusiewicz et al. using the CALPHAD approach [50]. For the sake of clarity, details at low 698 temperature have been omitted.

699 Fig. 2: Measured density, $\rho$, of liquid Al-Ti (symbols) and their linear fits (lines) versus 700 temperature, T, following Eq. (1). For the pure elements the fits for the mean values of all 701 measurements of $\mathrm{Al}$ and $\mathrm{Ti}$ are shown. The inset shows a magnified portion of the figure for 702 Al-mole fractions $x_{\mathrm{Al}}^{\mathrm{B}}$, ranging from 10 to 50 at.-\%.

703 Fig. 3: Molar volumes in dependence of the mole fraction, $x_{\mathrm{Al}}^{\mathrm{B}}$ of measurements at $T=1873 \mathrm{~K}$ 704 (solid circles), molar volumes extrapolated to a temperature range below (hollow circles) and 705 above (half-solid circles) measurement conditions. The lines show the ideal molar volumes 706 (dotted line) and fitted molar volumes with one fit parameter, ${ }^{0} \mathrm{~V}$, (solid line) and two fit 707 parameters, ${ }^{0} V$ and ${ }^{1} V$, (dashed-dotted-dotted line), following Eq. $(4,5)$.

708 Fig 4: Surface tension of pure liquid $\mathrm{Al}$ as function of temperature. The circles denote data 709 measured by Kolland [35] and the squares data measured by Kobatake [36] under oxygen 710 reduced conditions. The solid and the dashed-dotted lines represent corresponding fits to this 711 data. For comparison, representations of the surface tension data of Molina [54] are shown by 712 the dashed and dotted lines.

713 Fig. 5: Surface tension of liquid Ti (solid symbols) versus temperature. For comparison, data 714 of various authors are shown as well (hollow symbols). The long dashed line represents our 715 previous results determined in EML [27] and the results obtained by Paradis [53] using 716 electrostatic levitation are represented by the dashed-double-dotted line.

717 Fig. 6: Literature surface tension, $\gamma$, of liquid $\mathrm{Al}[24,35]$ and measured surface tension of 718 liquid Al-Ti (symbols) and their linear fits (lines) in dependence of temperature, $T$, following 
719 Eq. (8). The inset shows a magnified portion of the figure for Al-mole fractions $x_{\mathrm{Al}}^{\mathrm{B}}$, ranging 720 from 0 to 40 at.- $\%$.

721 Fig. 7: Isothermal surface tension $\gamma$ of measured liquid $\mathrm{Al}-\mathrm{Ti}$ and literature data for pure 722 liquid $\mathrm{Al}$, in dependence of the bulk mole fraction $x_{\mathrm{Al}}^{\mathrm{B}}$ at $1950 \mathrm{~K}\left(1677^{\circ} \mathrm{C}\right)$. The squares 723 show the extrapolated measured surface tension data, the lines represent the data fit with two

724 fit parameter, ${ }^{0} u$ and ${ }^{1} u$, (dashed-dotted-dotted line) following Eq. (21), surface tension values 725 calculated with the Butler model [39] for subregular solutions with ideal (dotted line) and 726 nonideal mixing behaviour (dashed line) and the Chatain model $[44,45]$ for subregular 727 solutions (solid line), as described in the text.

728 Fig. 8: Fitted excess molar volumes, $V^{\mathrm{E}}($ Eq. 15), of first order fits $(\mathrm{N}=1)$ at $T=1473 \mathrm{~K}$ $729\left(1200{ }^{\circ} \mathrm{C}\right)$ (dotted line), $1673 \mathrm{~K}\left(1400^{\circ} \mathrm{C}\right)$ (dashed line) and $1873 \mathrm{~K}\left(1600{ }^{\circ} \mathrm{C}\right)$ (solid line). $730 \quad$ Fig 9: Calculated surface mole fraction $x_{\mathrm{Al}}^{\mathrm{S}}$ as a function of the bulk mole fraction $x_{\mathrm{Al}}^{\mathrm{B}}$ at 731 $T=1950 \mathrm{~K}\left(1677^{\circ} \mathrm{C}\right)$ using the ideal (dotted line) and nonideal (dashed line) subregular

732 solution model by Butler [39] and by Chatain [44,45] (solid lines) for different layers, where 733 layer " 1 ” denotes the layer at the surface. The layer numbers increase with their distance to 734 the surface.

735 Fig 10: Calculated surface mole fraction $x_{\mathrm{Al}}^{(\mathrm{n})}$ as a function of the bulk mole fraction $x_{\mathrm{Al}}^{\mathrm{B}}$ at $736 T=1700 \mathrm{~K}\left(1477^{\circ} \mathrm{C}\right)$ (triangles) and $T=1950 \mathrm{~K}\left(1677^{\circ} \mathrm{C}\right)$ (squares) using the nonideal 737 subregular solution model by Chatain [44, 45] for different layers, where the layer numbers 738 increase with their distance to the surface.

739 Fig 11: Temperature coefficient values $\gamma_{\top}$ (Eq. (8) in dependence of the bulk mole fraction $740 \quad x_{\mathrm{Al}}^{\mathrm{B}}$ of measured data at $1950 \mathrm{~K}\left(1677^{\circ} \mathrm{C}\right)$, represented by the squares. The lines represent the 741 calculated temperature coefficient values for the nonideal subregular solution model by Butler 742 [39] (dashed line) and by Chatain [44, 45] (solid line). 
743 Fig 12: Isothermal excess surface tension $\gamma^{E}$ of liquid Al-Ti as a function of the bulk mole

744 fraction $x_{\mathrm{Al}}^{\mathrm{B}}$ at $T=1950 \mathrm{~K}\left(1677^{\circ} \mathrm{C}\right)$. The symbols show the extrapolated measured surface

745 tension data substracted by the calculated surface tension values of the Butler [39] (squares)

746 and Chatain $[44,45]$ (triangles) model for ideal subregular solutions. The lines represent

747 excess surface tension $\gamma^{E}$, (Eq. (20)), values calculated as the difference between the Butler

748 (dashed line) and Chatain (solid line) model for ideal and nonideal subregular solutions.

$749 \quad$ Fig. 13: Surface tension $\gamma$ of liquid Al-Ti in dependence of the bulk mole fraction $x_{\mathrm{Al}}^{\mathrm{B}}$ of 750 measured data at $1950 \mathrm{~K}\left(1677^{\circ} \mathrm{C}\right)$ and of Ti and industrially used Al-Ti-based alloys at

751 similar temperatures: Tiele [20], Allen [21], Amore [27], Arkhipkin [16], Paradis [17,52]

752 Kuppermann [23] Man [19], Nowak [60] Novakovic [25] and Egry [1,59].

753 
Table 1: Key of methods for the density and surface tension data, selected from literature and as used in the tables 2 and 7. The key R, meaning "recommended", species that the listed value is obtained from a literature review.

Table 2: Parameters $T_{\mathrm{L}}, \rho_{\mathrm{L}}$, and $\rho_{\mathrm{T}}$ and the interpolated density $\rho\left(T=1873 \mathrm{~K}\left(1600{ }^{\circ} \mathrm{C}\right)\right)$ and 760 its mean values in bold font of pure liquid $\mathrm{Al}$ and $\mathrm{Ti}$.

Table 3: Parameters $T_{\mathrm{L}}, \rho_{\mathrm{L}}$, and $\rho_{\mathrm{T}}$ and the extrapolated density $\rho\left(T=1873 \mathrm{~K}\left(1600{ }^{\circ} \mathrm{C}\right)\right)$ of 762 the investigated liquid alloys $\mathrm{Al}_{x} \mathrm{Ti}_{100-x}$.

763

764

765

766

767

Table 4: Parameters $\gamma_{\mathrm{L}}$, and $\gamma_{\mathrm{T}}$ and the extrapolated isothermal surface tension $\chi(T=1950 \mathrm{~K}$ $\left.\left(1677^{\circ} \mathrm{C}\right)\right)$ and its mean values in bold font for liquid Ti measured in this work and the selected data from literature for liquid $\mathrm{Al}$ used for the models and the references, respectively.

Table 5: Parameters $\gamma_{\mathrm{L}}$, and $\gamma_{\mathrm{T}}$ and the interpolated surface tension $\gamma\left(T=1950 \mathrm{~K}\left(1677^{\circ} \mathrm{C}\right)\right)$ of the investigated liquid alloys $\mathrm{Al}_{x} \mathrm{Ti}_{100-x}$.

Table 6: Parameters $T_{\mathrm{L}}$ and $\rho_{\mathrm{L}}$ and its mean values in bold font for the density of pure $\mathrm{Al}$ and Ti selected from literature. The methods and references are specified in the fourth and fifth column and the method key can be found in Tab. 3 .

Table 7: Coefficients ${ }^{\vee} V(T)$ of Redlich-Kister type polynomial fit, following Eq. (5) for fitted excess molar volumes, $V^{\mathrm{E}}$, temperature dependent parameters ${ }^{v} L$ used for the calculations of the subregular solution models by Butler and by Chatain (Eq. (15) and coefficients ${ }^{\mathrm{v}} u(\mathrm{~T})$ of Table 8: Compilation of surface tension values $\gamma_{\mathrm{L}}$ and $\gamma_{\mathrm{T}}$ and the corresponding references and methods for liquid Titanium. The method key is listed in Tab. 3, respectively. RedlichKister type polynomial fit following Eq. (21) for fitted excess surface tension, $\gamma^{E}$. 
Table 1

\begin{tabular}{|l|l|}
\hline Key & Method \\
\hline CR & Rise method \\
\hline DC & Draining crucible \\
\hline ESL & Electro static \\
\hline DW & Drop weight \\
\hline PW & Pedant wire \\
\hline EML & Electro magnetic \\
\hline OD & Oscillating drop \\
\hline PD & Pendant drop \\
\hline A & Archimedian methods \\
\hline BP & Bubble Pressure \\
\hline SD & Sessile drop \\
\hline G & $\gamma$-Absorption dilatometry \\
\hline EW & Exploding wire \\
\hline R & Recommended from literature review \\
\hline
\end{tabular}


Table 2

\begin{tabular}{|c|c|c|c|c|}
\hline Composition & $T_{\mathrm{L}}\left(\mathrm{K}\left({ }^{\circ} \mathrm{C}\right)\right)$ & $\rho_{\mathrm{L}}\left(\mathrm{gcm}^{-3}\right)$ & $\rho_{\mathrm{T}}\left(10^{-4} \mathrm{gcm}^{-3} \mathrm{~K}^{-}\right.$ & $\rho(T=1873 \mathrm{~K}(1600$ \\
& & & $\left.{ }^{1}\right)$ & $\left.\left.{ }^{\circ} \mathrm{C}\right)\right)\left(\mathrm{g} / \mathrm{cm}^{3}\right)$ \\
\hline $\mathrm{Ti}$ & $1941(1668)$ & 4.14 & -1.48 & 4.15 \\
\hline $\mathrm{Ti}$ & $1941(1668)$ & 4.15 & -4.4 & 4.18 \\
\hline $\mathrm{Ti}$ & $1941(1668)$ & 4.06 & -3.14 & 4.14 \\
\hline $\mathrm{Ti}$ & $1941(1668)$ & 4.13 & -2.38 & $\mathbf{4 . 1 4} \pm \mathbf{0 . 0 4}$ \\
\hline $\mathbf{T i}$ & $\mathbf{1 9 4 1}(\mathbf{1 6 6 8})$ & $\mathbf{4 . 1 2} \pm \mathbf{0 . 0 4}$ & $\mathbf{- 2 . 8 5} \pm \mathbf{1 . 2 3}$ & 2.08 \\
\hline $\mathrm{Al}$ & $933(660)$ & 2.32 & -2.52 & 2.10 \\
\hline $\mathrm{Al}$ & $933(660)$ & 2.28 & -1.88 & 2.09 \\
\hline $\mathrm{Al}$ & $933(660)$ & 2.29 & -2.14 & $\mathbf{2 . 0 9} \pm \mathbf{0 . 0 1}$ \\
\hline $\mathrm{Al}$ & $\mathbf{9 3 3 ( 6 6 0 )}$ & $\mathbf{2 . 3 0} \pm \mathbf{0 . 0 2}$ & $\mathbf{- 2 . 1 8} \pm \mathbf{0 . 3 2}$ & \\
\hline & & & & \\
\hline
\end{tabular}


Table 3

\begin{tabular}{|c|c|c|c|c|}
\hline Composition & $T_{\mathrm{L}}\left(\mathrm{K}\left({ }^{\circ} \mathrm{C}\right)\right)$ & $\rho_{\mathrm{L}}\left(\mathrm{gcm}^{-3}\right)$ & $\rho_{\mathrm{T}}\left(10^{-4} \mathrm{gcm}^{-3} \mathrm{~K}^{-1}\right)$ & $\begin{array}{c}\rho(T=1873 \mathrm{~K}(1600 \\
\left.\left.{ }^{\circ} \mathrm{C}\right)\right)\left(\mathrm{g} / \mathrm{cm}^{3}\right)\end{array}$ \\
\hline $\mathrm{Al}_{10} \mathrm{Ti}_{90}$ & 1962 (1689) & 3.91 & -4.98 & 3.96 \\
\hline $\mathrm{Al}_{10} \mathrm{Ti}_{90}$ & 1962 (1689) & 3.82 & -2.78 & 3.84 \\
\hline $\mathrm{Al}_{20} \mathrm{Ti}_{80}$ & 1948 (1675) & 3.63 & -3.91 & 3.66 \\
\hline $\mathrm{Al}_{20} \mathrm{Ti}_{80}$ & 1948 (1675) & 3.67 & -3.17 & 3.69 \\
\hline $\mathrm{Al}_{25} \mathrm{Ti}_{75}$ & 1941 (1668) & 3.69 & -5.49 & 3.73 \\
\hline $\mathrm{Al}_{25} \mathrm{Ti}_{75}$ & 1941 (1668) & 3.65 & -3.37 & 3.67 \\
\hline $\mathrm{Al}_{25} \mathrm{Ti}_{75}$ & 1941 (1668) & 3.61 & -5.53 & 3.65 \\
\hline $\mathrm{Al}_{30} \mathrm{Ti}_{70}$ & 1915 (1642) & 3.52 & -7.57 & 3.55 \\
\hline $\mathrm{Al}_{30} \mathrm{Ti}_{70}$ & 1915 (1642) & 3.53 & -3.2 & 3.54 \\
\hline $\mathrm{Al}_{40} \mathrm{Ti}_{60}$ & $1853(1580)$ & 3.37 & -1.18 & 3.36 \\
\hline $\mathrm{Al}_{50} \mathrm{Ti}_{50}$ & 1757 (1484) & 3.34 & -4.91 & 3.36 \\
\hline $\mathrm{Al}_{50} \mathrm{Ti}_{50}$ & 1757 (1484) & 3.38 & -4.51 & 3.32 \\
\hline $\mathrm{Al}_{60} \mathrm{Ti}_{40}$ & 1721 (1448) & 3.13 & -5.56 & 3.04 \\
\hline $\mathrm{Al}_{70} \mathrm{Ti}_{30}$ & $1689(1416)$ & 2.91 & -3.53 & 2.85 \\
\hline $\mathrm{Al}_{70} \mathrm{Ti}_{30}$ & 1689 (1416) & 2.88 & -3.37 & 2.82 \\
\hline $\mathrm{Al}_{80} \mathrm{Ti}_{20}$ & $1654(1381)$ & 2.69 & -5.82 & 2.57 \\
\hline $\mathrm{Al}_{80} \mathrm{Ti}_{20}$ & 1654 (1381) & 2.69 & -5.58 & 2.57 \\
\hline $\mathrm{Al}_{90} \mathrm{Ti}_{10}$ & 1562 (1289) & 2.46 & -3.41 & 2.36 \\
\hline
\end{tabular}


Table 4

\begin{tabular}{|c|c|c|c|c|c|}
\hline Element & $T_{\mathrm{L}}\left(\mathrm{K}\left({ }^{\circ} \mathrm{C}\right)\right)$ & $\gamma_{\mathrm{L}}\left(\mathrm{Nm}^{-1}\right)$ & $\gamma_{\mathrm{T}}\left(10^{-4} \mathrm{Nm}^{-1} \mathrm{~K}^{-1}\right)$ & $\begin{array}{c}x(T=1950 \mathrm{~K} \\
\left.\left(1677^{\circ} \mathrm{C}\right)\right) \\
\left(\mathrm{Nm}^{-1}\right)\end{array}$ & Reference \\
\hline $\mathrm{Ti}$ & 1941 (1668) & 1.56 & -0.62 & 1.56 & Present work \\
\hline $\mathrm{Ti}$ & $1941(1668)$ & 1.58 & -2.49 & 1.57 & Present work \\
\hline $\mathrm{Ti}$ & 1941 (1668) & 1.54 & -1.85 & 1.54 & Present work \\
\hline $\mathbf{T i}$ & 1941 (1668) & $1.56 \pm 0.02$ & $-1.65 \pm 0.95$ & $1.55 \pm 0.02$ & \\
\hline $\mathrm{Al}$ & $933(660)$ & 0.98 & -2.71 & 0.70 & [37] \\
\hline $\mathrm{Al}$ & 933 (660) & 0.87 & -1.46 & 0.72 & [35] \\
\hline Al & $933(660)$ & $0.92 \pm 0.08$ & $-2.09 \pm 0.88$ & $0.71 \pm 0.02$ & \\
\hline
\end{tabular}


Table 5

\begin{tabular}{|c|c|c|c|c|}
\hline Composition & $T_{\mathrm{L}}\left(\mathrm{K}\left({ }^{\circ} \mathrm{C}\right)\right)$ & $\gamma_{\mathrm{L}}\left(\mathrm{Nm}^{-1}\right)$ & $\gamma_{\mathrm{T}}\left(10^{-4} \mathrm{Nm}^{-1} \mathrm{~K}^{-1}\right)$ & $\begin{array}{c}\chi(T=1950 \mathrm{~K}(1677 \\
\left.\left.{ }^{\circ} \mathrm{C}\right)\right)\left(\mathrm{Nm}^{-1}\right)\end{array}$ \\
\hline $\mathrm{Al}_{10} \mathrm{Ti}_{90}$ & 1962 (1689) & 1.52 & -4.34 & 1.53 \\
\hline $\mathrm{Al}_{10} \mathrm{Ti}_{90}$ & 1962 (1689) & 1.46 & -5.81 & 1.47 \\
\hline $\mathrm{Al}_{20} \mathrm{Ti}_{80}$ & 1948 (1675) & 1.35 & -3.29 & 1.35 \\
\hline $\mathrm{Al}_{20} \mathrm{Ti}_{80}$ & $1948(1675)$ & 1.28 & -2.18 & 1.28 \\
\hline $\mathrm{Al}_{25} \mathrm{Ti}_{75}$ & 1941 (1668) & 1.30 & -2.42 & 1.30 \\
\hline $\mathrm{Al}_{25} \mathrm{Ti}_{75}$ & 1941 (1668) & 1.36 & -3.38 & 1.36 \\
\hline $\mathrm{Al}_{30} \mathrm{Ti}_{70}$ & 1915 (1642) & 1.34 & -3.38 & 1.33 \\
\hline $\mathrm{Al}_{30} \mathrm{Ti}_{70}$ & 1915 (1642) & 1.33 & -4.24 & 1.31 \\
\hline $\mathrm{Al}_{40} \mathrm{Ti}_{60}$ & 1853 (1580) & 1.24 & -1.79 & 1.23 \\
\hline $\mathrm{Al}_{50} \mathrm{Ti}_{50}$ & 1757 (1484) & 1.07 & -2.86 & 1.01 \\
\hline $\mathrm{Al}_{60} \mathrm{Ti}_{40}$ & 1721 (1448) & 0.96 & -0.68 & 0.95 \\
\hline $\mathrm{Al}_{70} \mathrm{Ti}_{30}$ & 1689 (1416) & 0.94 & -1.80 & 0.89 \\
\hline $\mathrm{Al}_{80} \mathrm{Ti}_{20}$ & 1654 (1381) & 0.92 & -1.61 & 0.88 \\
\hline $\mathrm{Al}_{90} \mathrm{Ti}_{10}$ & 1562 (1289) & 0.89 & -3.14 & 0.77 \\
\hline $\mathrm{Al}_{90} \mathrm{Ti}_{10}$ & 1562 (1289) & 0.81 & -0.23 & 0.80 \\
\hline
\end{tabular}


Table 6

\begin{tabular}{|c|c|c|c|c|}
\hline Composition & $\rho_{\mathrm{L}}\left(\mathrm{gcm}^{-3}\right)$ & $\rho_{\mathrm{T}}\left(10^{-4} \mathrm{gcm}^{-3} \mathrm{~K}^{-1}\right)$ & Reference & Method \\
\hline $\mathrm{Al}$ & 2.37 & -2.6 & [35] & A \\
\hline $\mathrm{Al}$ & 2.39 & -3.9 & [36] & $\mathrm{BP}$ \\
\hline $\mathrm{Al}$ & 2.37 & -2.6 & [37] & SD \\
\hline $\mathrm{Al}$ & 2.38 & -3.3 & [38] & SD \\
\hline $\mathrm{Al}$ & 2.37 & -3.1 & [39] & $G$ \\
\hline $\mathrm{Al}$ & 2.38 & -2.3 & [40] & G \\
\hline $\mathrm{Al}$ & 2.38 & -2.3 & [41] & $\mathrm{R}$ \\
\hline $\mathrm{Al}$ & 2.37 & -3.1 & [42] & $\mathrm{R}$ \\
\hline $\mathrm{Al}$ & 2.36 & -3.3 & [4] & EML \\
\hline $\mathrm{Al}$ & 2.36 & -3.0 & [4] & EML \\
\hline $\mathrm{Al}$ & 2.29 & -2.5 & [4] & EML \\
\hline Al & $2.36 \pm 0.03$ & $-2.91 \pm 0.50$ & & \\
\hline $\mathrm{Ti}$ & 4.17 & -2.2 & [43] & ESL \\
\hline $\mathrm{Ti}$ & 4.10 & -9.9 & [44] & ESL \\
\hline $\mathrm{Ti}$ & 4.21 & -5.1 & [52] & ESL \\
\hline $\mathrm{Ti}$ & 4.14 & -2.25 & [41] & $\mathrm{R}$ \\
\hline $\mathrm{Ti}$ & 4.29 & -2.3 & [45] & WE \\
\hline $\mathrm{Ti}$ & 4.1 & -3.3 & [4] & EML \\
\hline $\mathbf{T i}$ & $4.17 \pm 0.07$ & $-4.18 \pm 3.02$ & & \\
\hline
\end{tabular}


Table 7

\begin{tabular}{|c|c|c|c|}
\hline$v$ & ${ }^{v} V(T)\left(\mathrm{m}^{3} \mathrm{~mol}^{-1}\right)$ & ${ }^{v} L\left(\mathrm{Jmol}^{-1}\right)$ & ${ }^{v} u(T)\left(\mathrm{Nm}^{-1} \mathrm{~mol}^{-1}\right)$ \\
\hline 0 & $0.00247 T-6.55516$ & $41.972 T-118048$ & $-0.00136 T+2.8091$ \\
\hline 1 & $-0.001 T+4.3711$ & $19.704 T-23613$ & $-2.18327 \cdot 10^{-4} T+0.21604$ \\
\hline 2 & & $-13.844 T+34757$ & \\
\hline
\end{tabular}


Table 8

\begin{tabular}{|c|c|c|c|c|}
\hline $\begin{array}{c}\gamma_{\mathrm{L}} \\
\left(10^{-4} \mathrm{Nm}^{-1} \mathrm{~K}^{-1}\right)\end{array}$ & $\begin{array}{c}\gamma_{\mathrm{T}} \\
\left(10^{-4} \mathrm{Nm}^{-1} \mathrm{~K}^{-1}\right)\end{array}$ & $T\left(\mathrm{~K}\left({ }^{\circ} \mathrm{C}\right)\right)$ & Reference & Method \\
\hline 1.51 & - & $1940(1667)$ & Elyutin et al. [15] & CR \\
\hline 1.41 & - & 1941 (1668) & Arkhipkin et al. [16] & DC \\
\hline 1.557 & -0.156 & $1943(1670)$ & Paradis et al. [17,52] & ESL \\
\hline 1.525 & - & $1943(1670)$ & Vinet et al. [18] & DW/PW \\
\hline 1.475 & - & $1943(1670)$ & Man et al. [19] & PD \\
\hline 1.49 & -0.17 & $1943(1670)$ & Brillo et al. [27] & EML-OD \\
\hline 1.588 & - & $1953(1680)$ & Tiele et al. [20] & DW \\
\hline 1.65 & - & $1953(1680)$ & Allen et al. [21] & PD \\
\hline 1.39 & - & $1953(1680)$ & Peterson et al. [22] & PD \\
\hline 1.675 & - & $1953(1680)$ & Kupperman et al. [23] & Levitation \\
\hline 1.58 & -2.49 & 1941 (1668) & Present work & EML-OD \\
\hline 1.54 & -1.85 & 1941 (1668) & Present work & EML-OD \\
\hline 1.56 & -0.62 & $1941(1668)$ & Present work & EML-OD \\
\hline
\end{tabular}




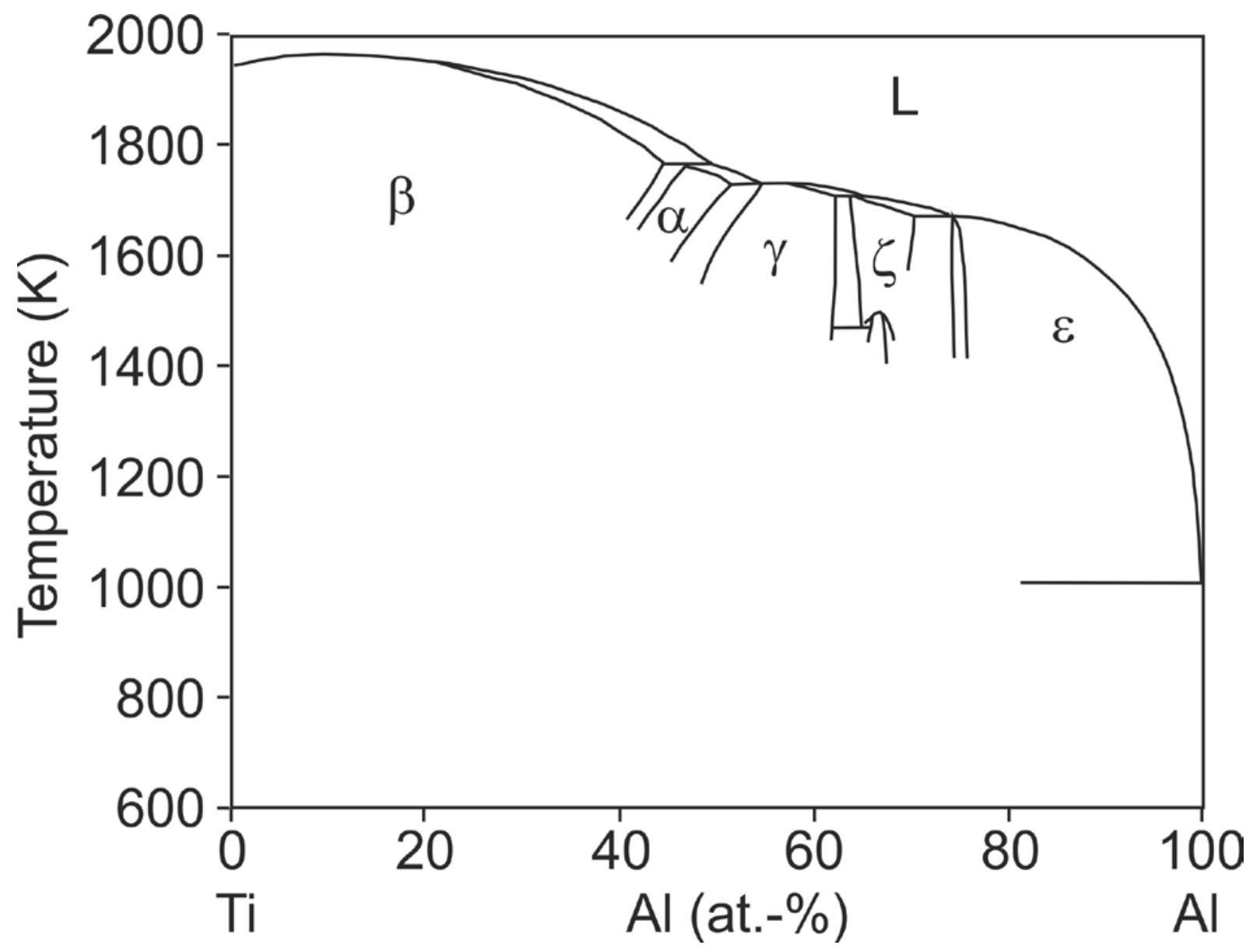

Figure 1 


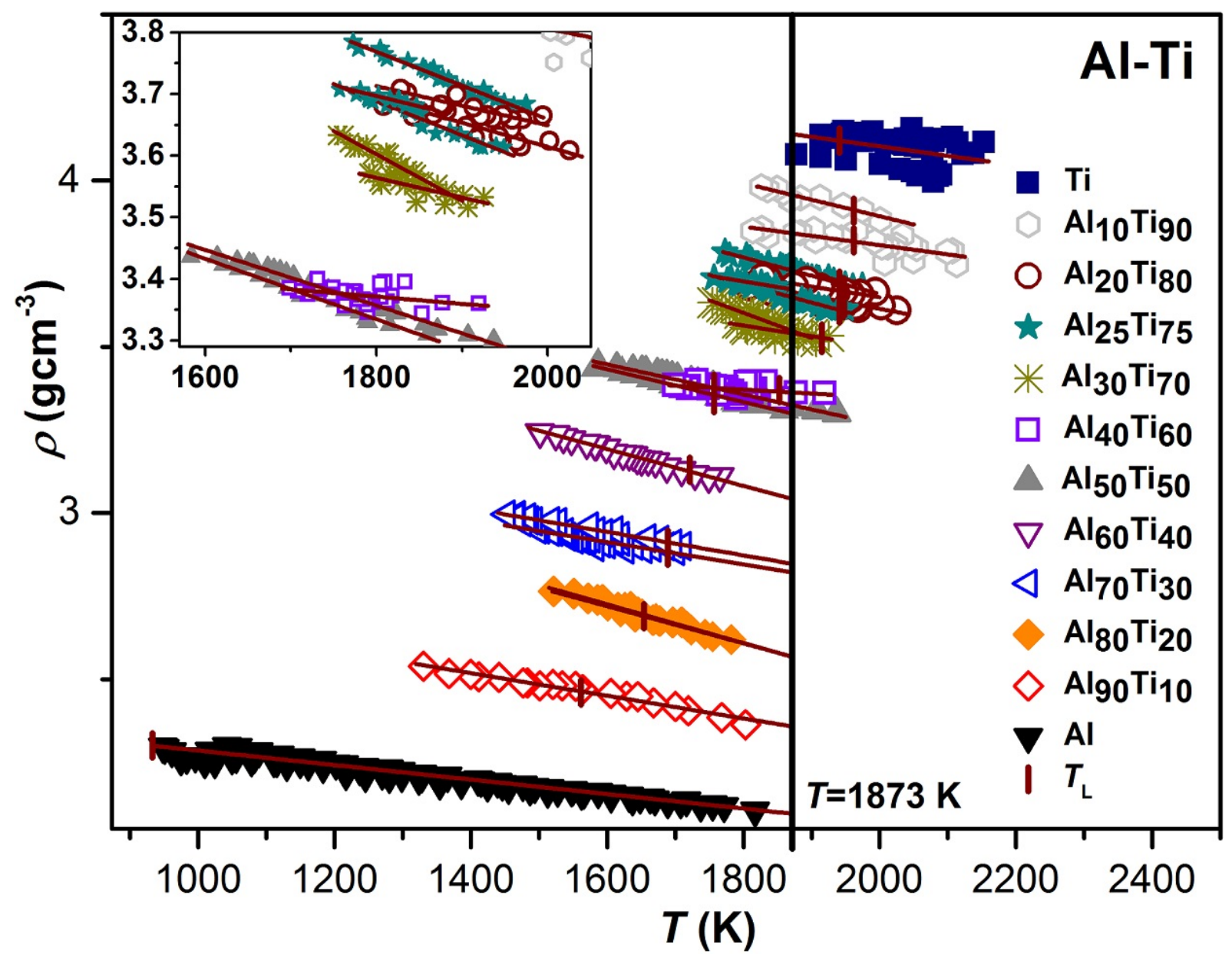

Figure 2 


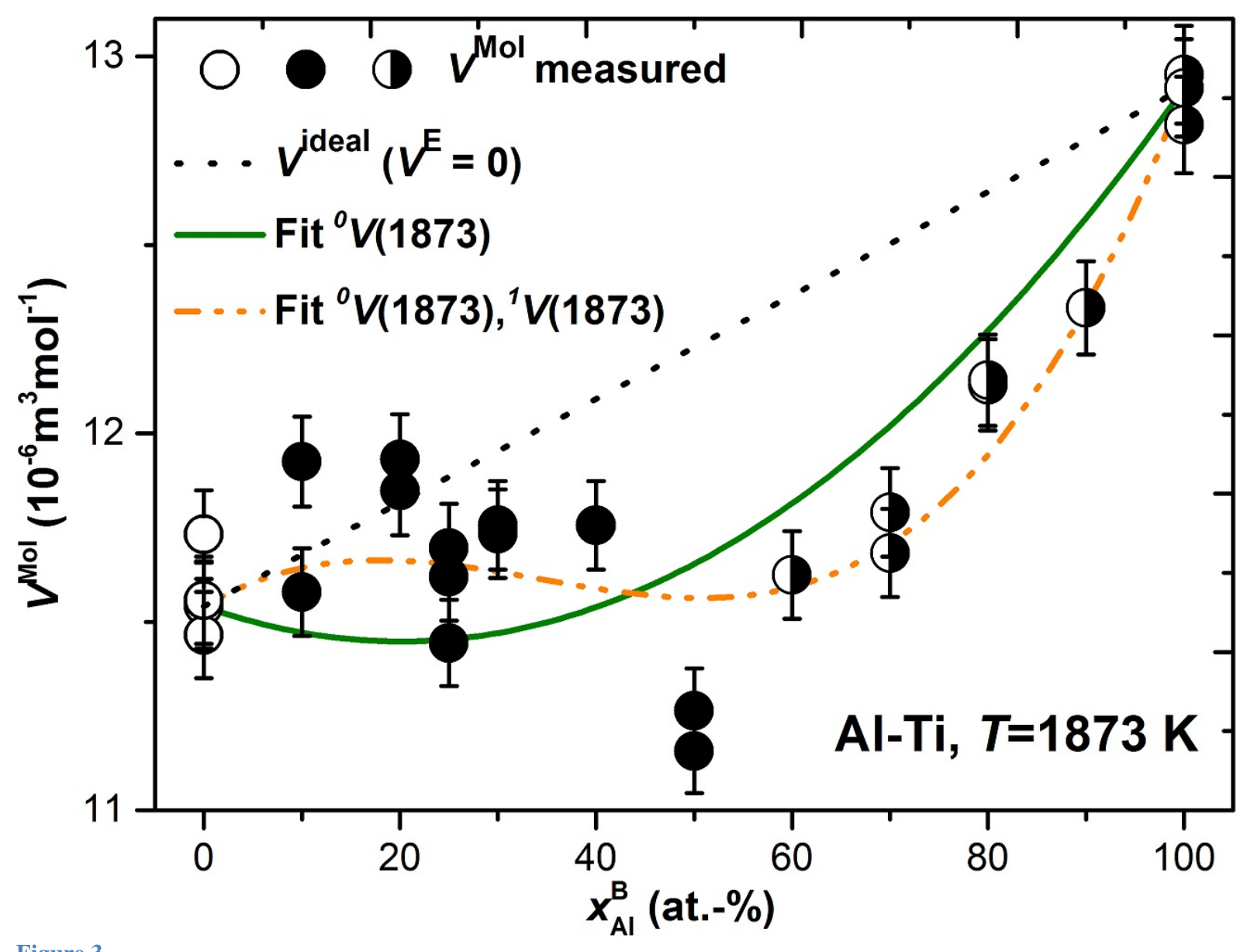

Figure 3 


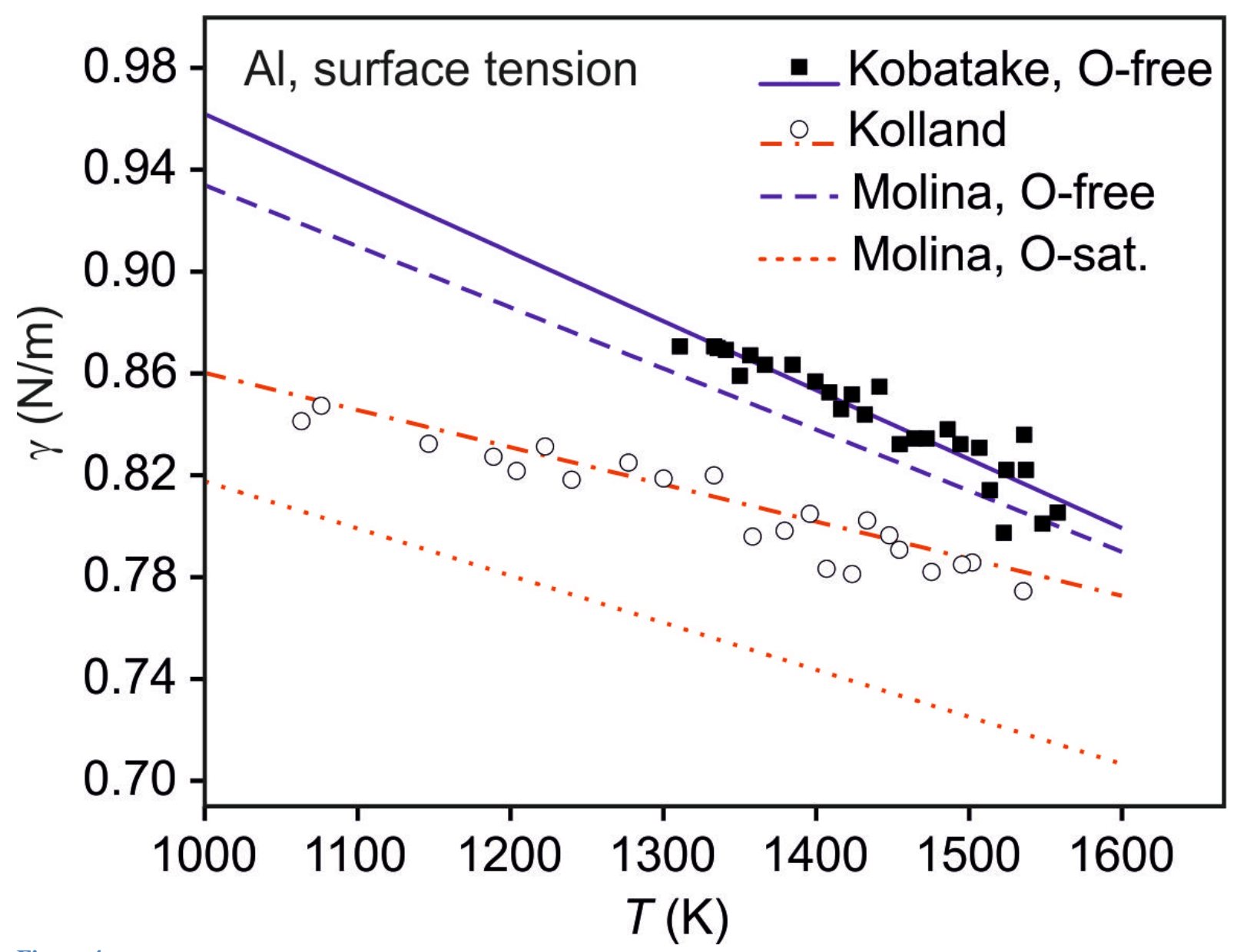

Figure 4 


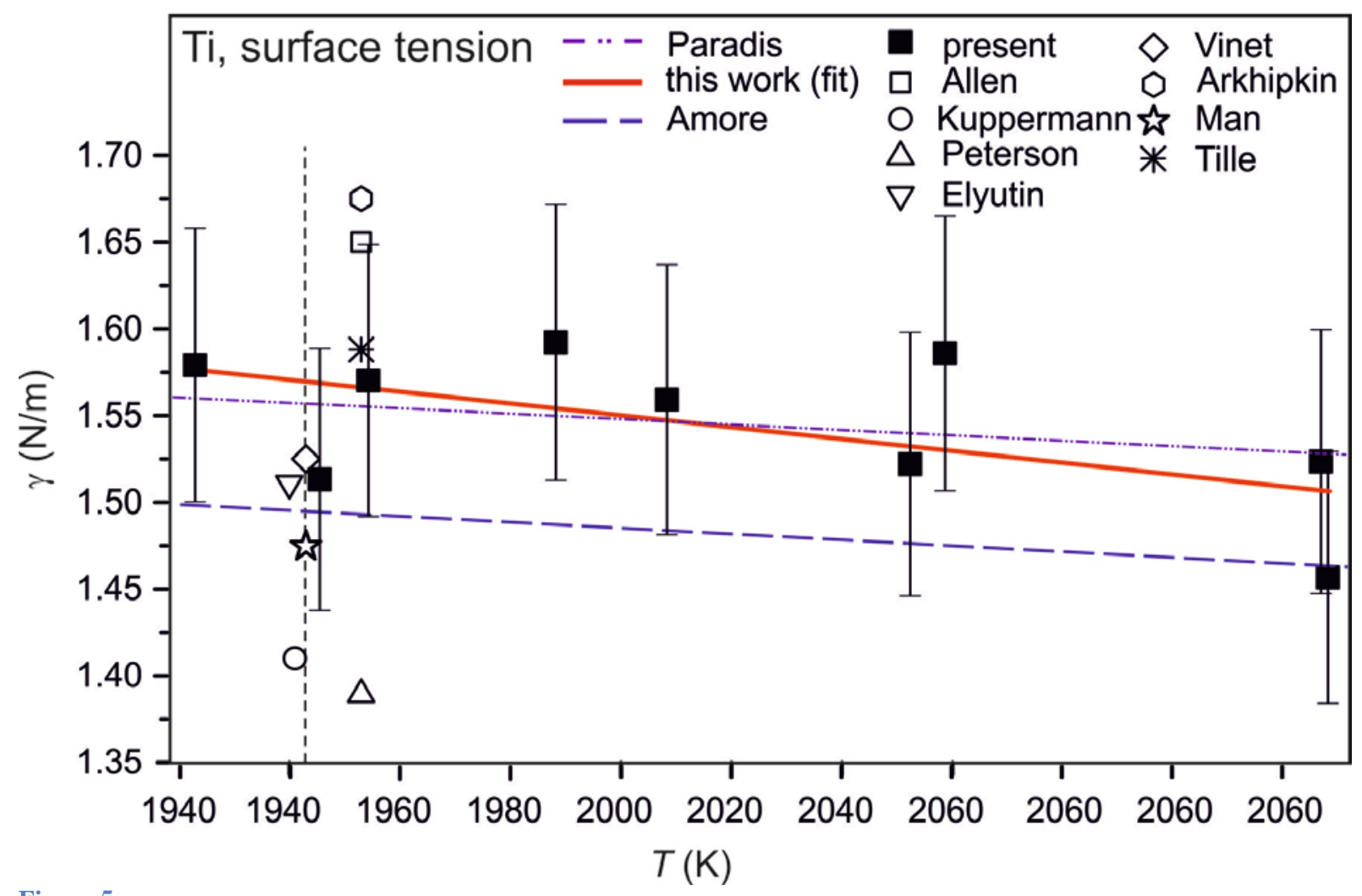

Figure 5 


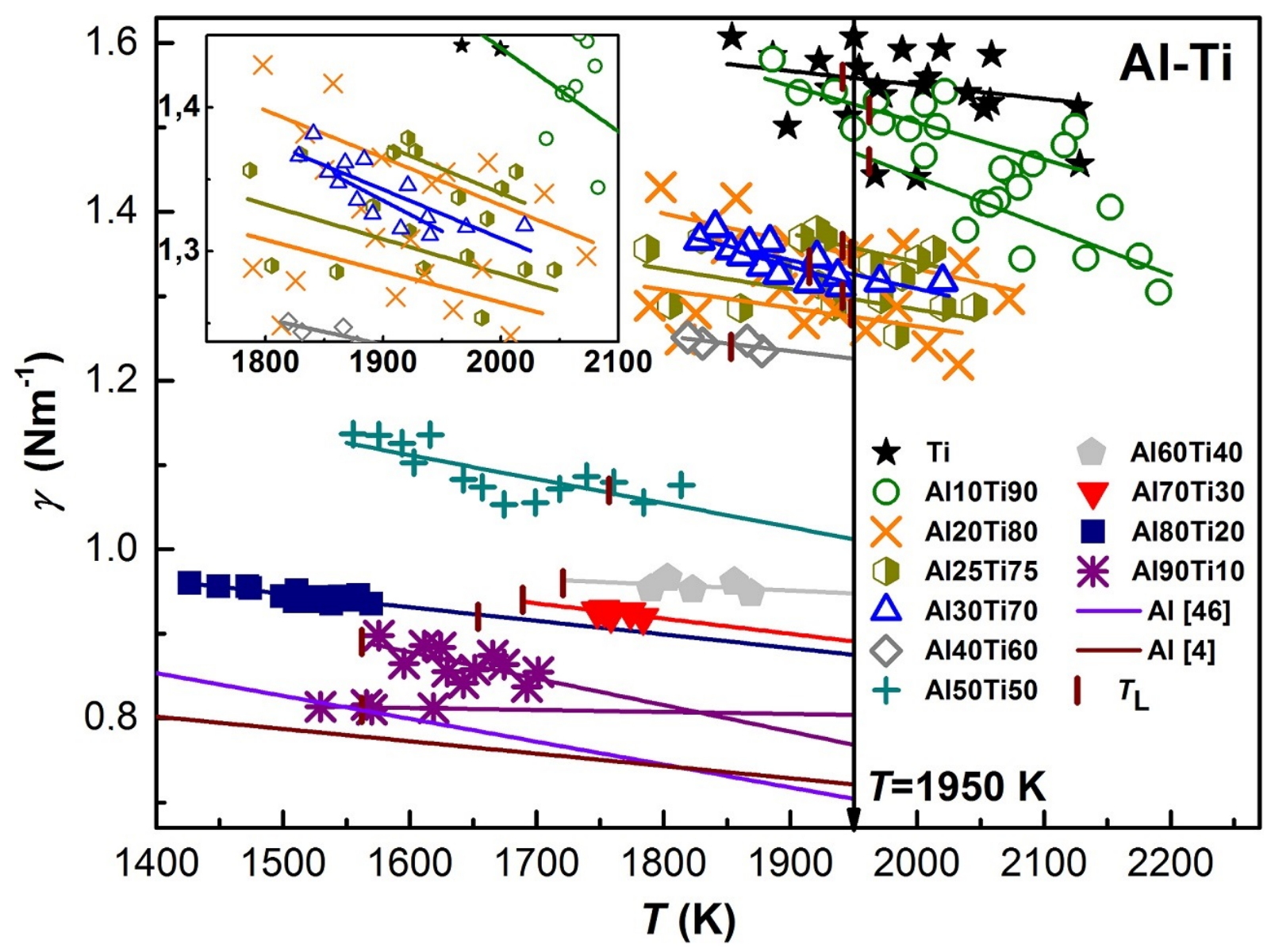

Figure 6 


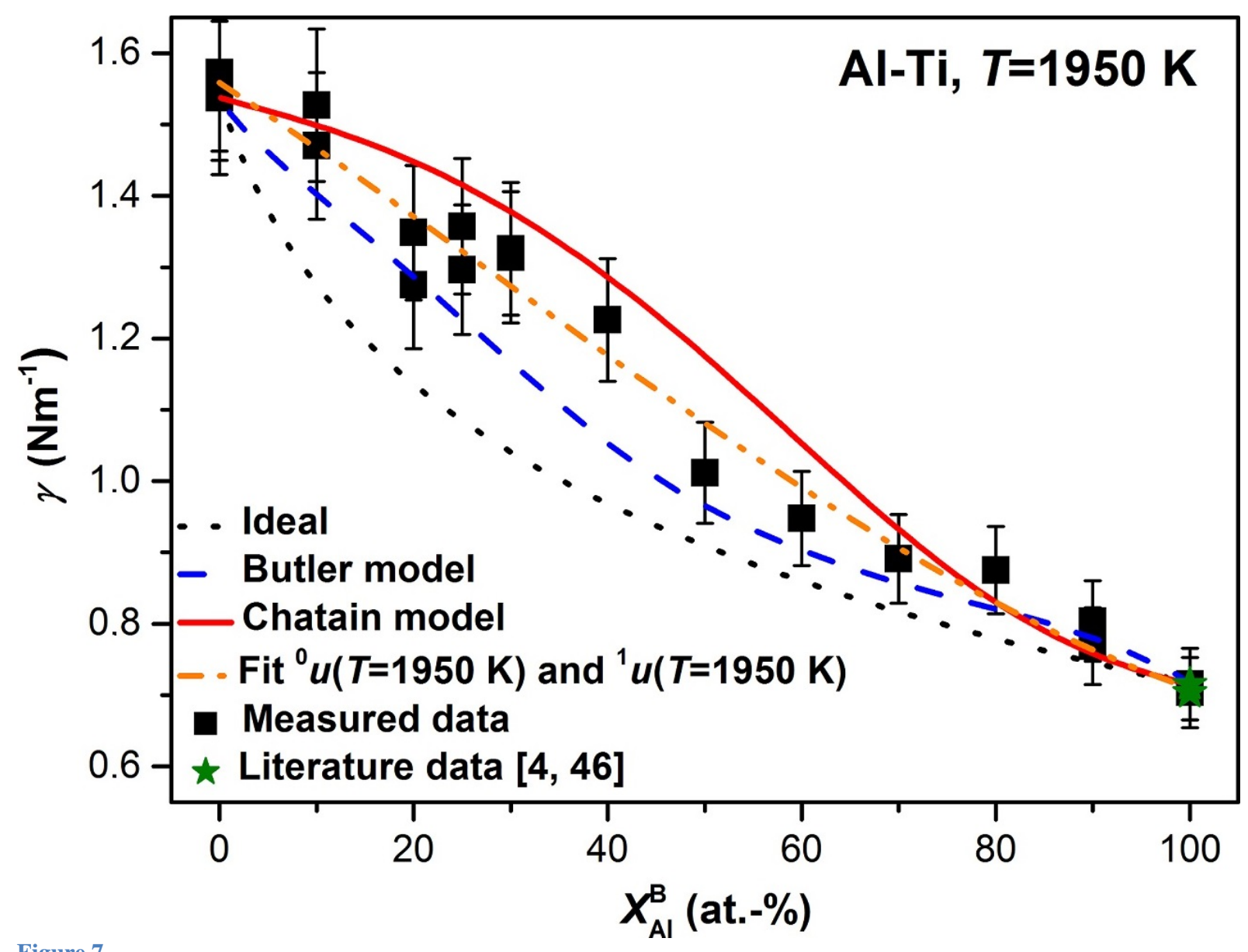

Figure 7 


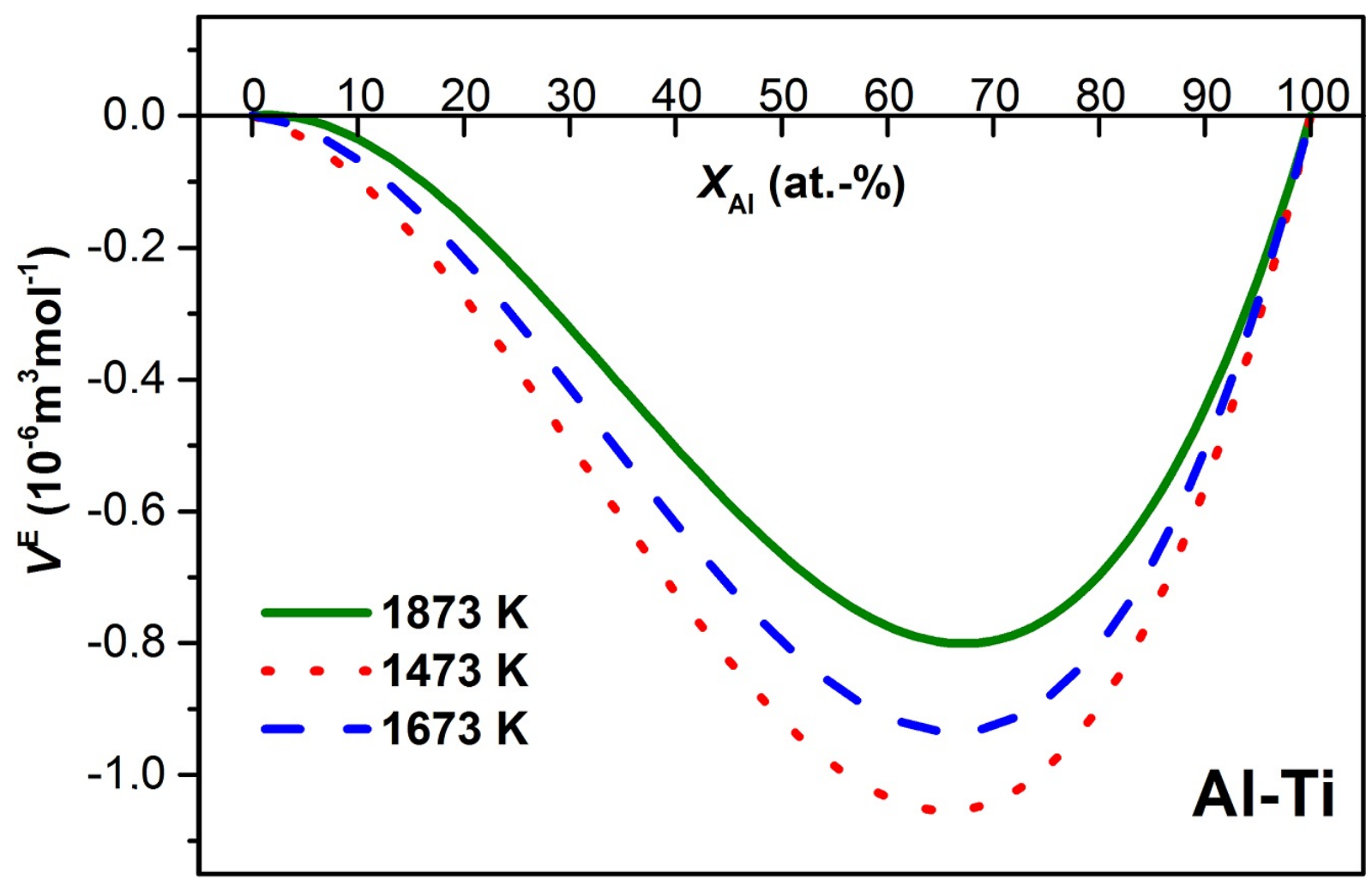

Figure 8 


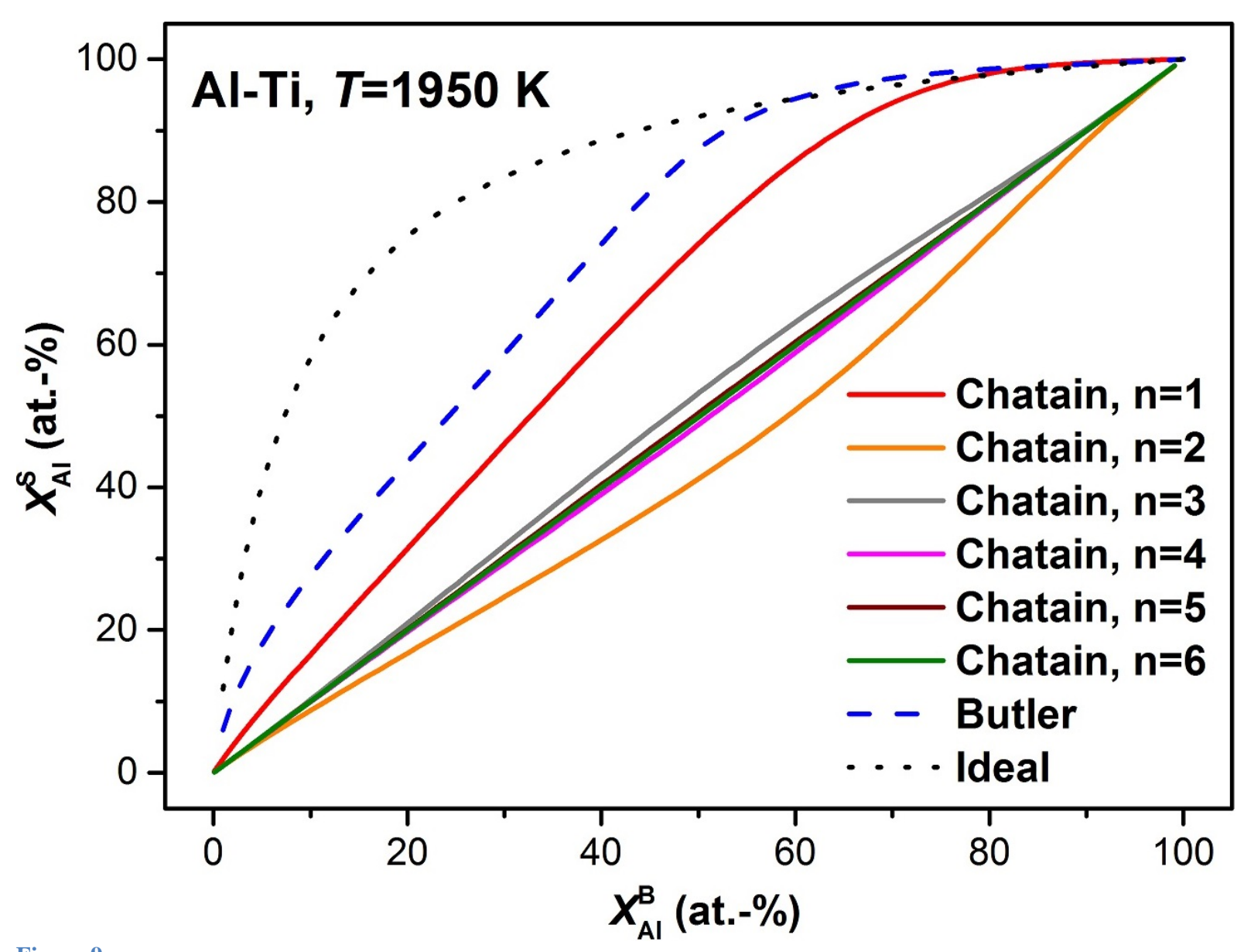

Figure 9 


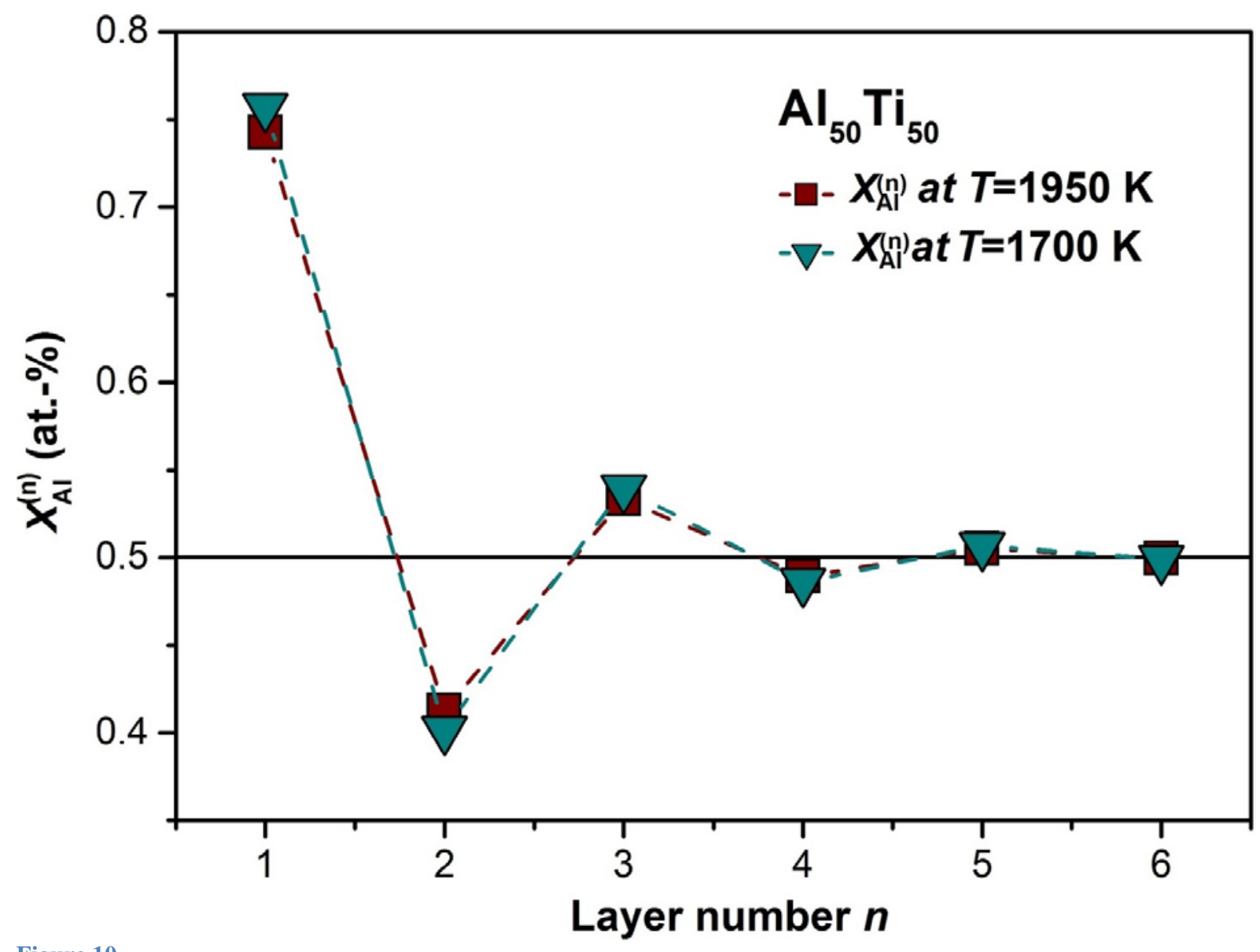

Figure 10 


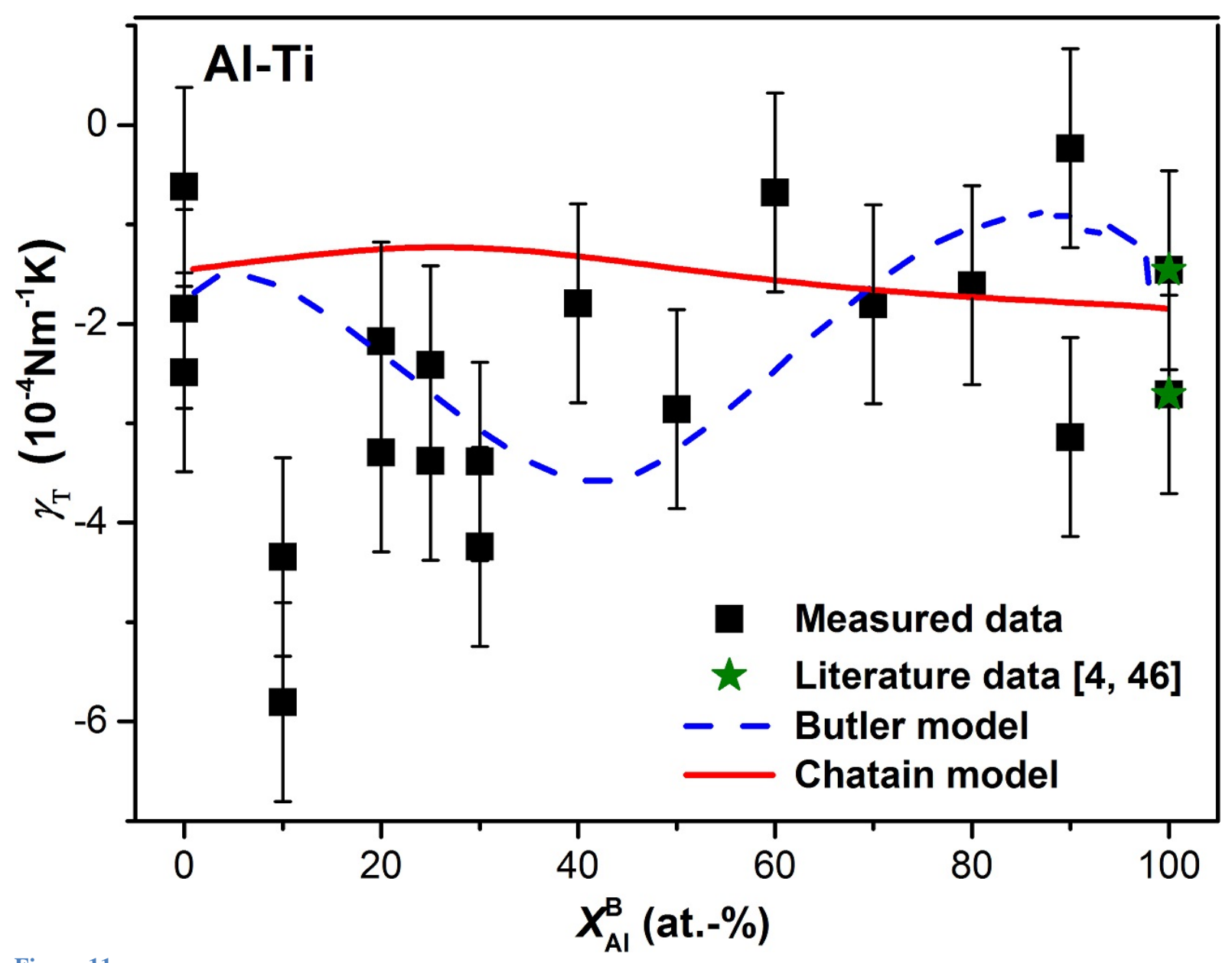

Figure 11 


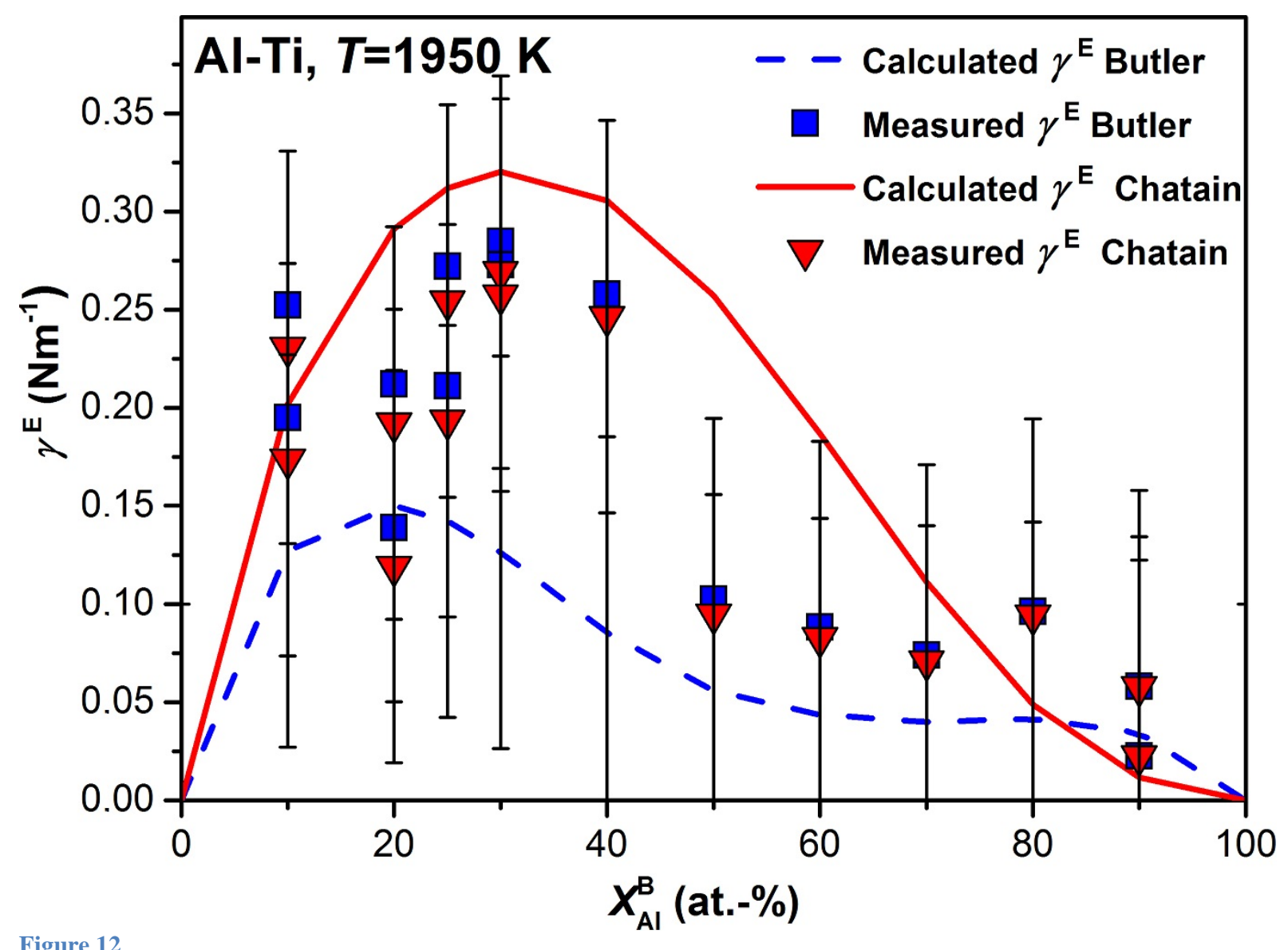

Figure 12 


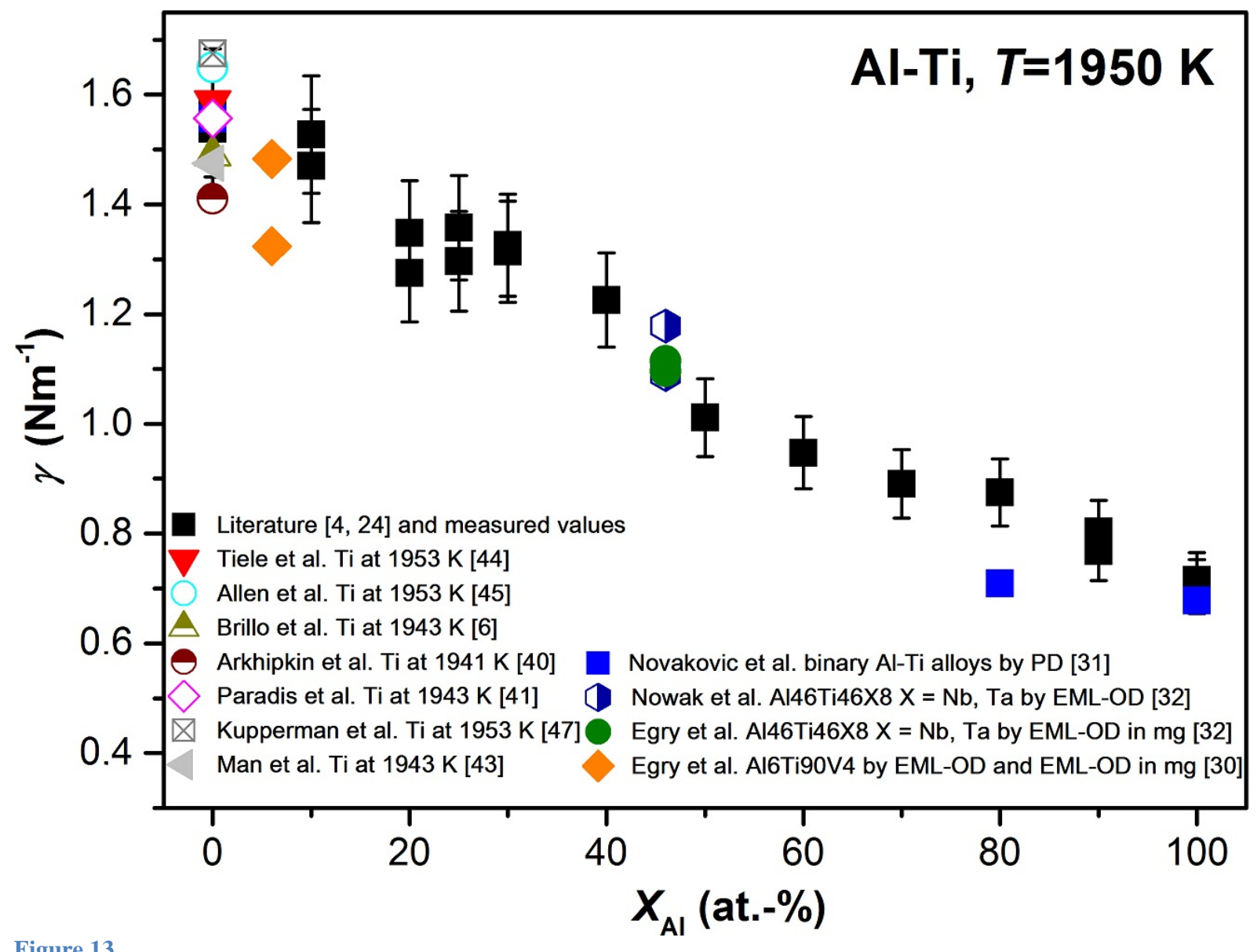

Figure 13 